\title{
Lipopolysaccharide Is a 4-Aminoarabinose Donor to Exogenous Polyisoprenyl Phosphates through the Reverse Reaction of the Enzyme ArnT
}

\author{
Beth A. Scarbrough, Colleen R. Eade, Amanda J. Reid, Tiffany C. Williams, and Jerry M. Troutman*
}

Cite This: ACS Omega 2021, 6, 25729-25741

Read Online

山ll Metrics \& More

回 Article Recommendations

SI Supporting Information

ABSTRACT: Modification of the lipid A portion of LPS with cationic monosaccharides provides resistance to polymyxins, which are often employed as a last resort to treat multidrug-resistant bacterial infections. Here, we describe the use of fluorescent polyisoprenoids, liquid chromatography-mass spectrometry, and bacterial genetics to probe the activity of membrane-localized proteins that utilize the 55-carbon lipid carrier bactoprenyl phosphate (BP). We have discovered that a substantial background reaction occurs when B-strain $E$. coli cell membrane fractions are supplemented with exogenous BP. This reaction involves proteins associated with the arn operon, which is necessary for the covalent modification of lipid A with the cationic 4-aminoarabinose
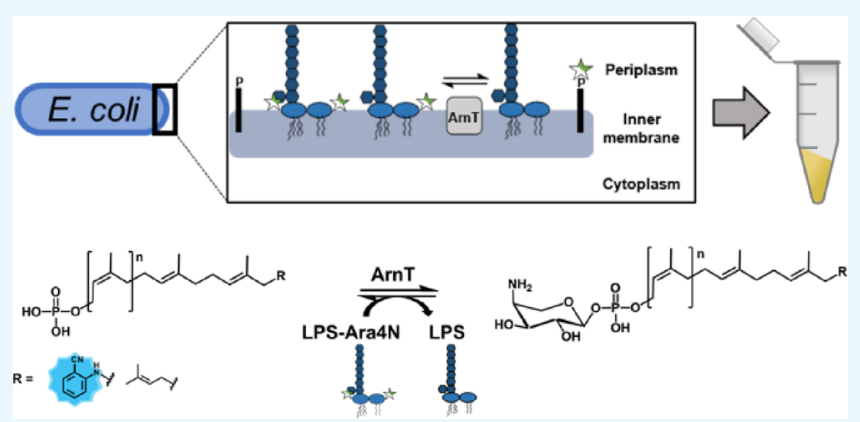
(Ara4N). Using a series of arn operon gene deletion mutants, we identified that the modification was dependent on ArnC, which is responsible for forming BP-linked Ara4N, or ArnT, which transfers Ara4N to lipid A. Surprisingly, we found that the majority of the Ara $4 \mathrm{~N}$-modified isoprenoid was due to the reverse reaction catalyzed by ArnT and demonstrate this using heatinactivated membrane fractions, isolated lipopolysaccharide fractions, and analyses of a purified ArnT. This work provides methods that will facilitate thorough and rapid investigation of bacterial outer membrane remodeling and the evaluation of polyisoprenoid precursors required for covalent glycan modifications.

\section{INTRODUCTION}

Bactoprenyl phosphate (BP, also known as undecaprenyl phosphate) is an essential precursor required to synthesize vital surface polysaccharides including peptidoglycan, capsules, and teichoic acids. BP is also required to glycosylate a variety of outer membrane components. Notably, the 55-carbon BP lipid carrier is necessary for the covalent modification of lipid A with cationic glycoses such as 4-aminoarabinose (Ara4N), glucosamine, and galactosamine in many species of Gram-negative pathogens. ${ }^{1-6}$ These outer membrane modifications are frequently associated with resistance to cationic antimicrobial peptides (CAMPs) such as polymyxin B and colistin (polymyxin E) and in certain species are required for cell viability. $4,7,8$ Currently, polymyxin and colistin are being used as last-resort treatments against multidrug-resistant Gram-negative bacterial infections. ${ }^{9}$ Consequently, enzymes within lipid A modification pathways are being targeted for the development of inhibitors to resensitize CAMP-resistant Gram-negative pathogens. ${ }^{10,11}$

In Salmonella enterica and Escherichia coli, CAMP resistance is due to covalent modification of the lipid A portion of LPS with Ara4N (Reviewed by Raetz et al.). ${ }^{12}$ In those species, incorporation of Ara4N into the outer membrane begins in the cytosol with the biosynthesis of UDP-L-4-formamidoarabinose (UDP-Ara4FN) from UDP-glucose via the well- characterized enzymes Ugd, ArnA (PmrI), and ArnB $(\mathrm{PmrH}) .{ }^{13-17}$ Membrane-bound ArnC (PmrF) will then append Ara4FN to $\mathrm{BP}$ to produce bactoprenyl monophosphate-4-formamido-arabinose (BP-Ara4FN) (Figure 1). ${ }^{14}$ Subsequently, ArnD (PmrJ) will deformylate 4-formamidoarabinose to produce bactoprenyl monophosphate-4-aminoarabinose (BP-Ara4N), which is then flipped into the periplasm by the proposed ArnE/F (PmrM/L) flippase heterodimer. ${ }^{18,19}$ The deformylation of the BP-Ara4FN intermediate likely commits this pathway to lipid A modification and prevents reversal of the ArnC reaction. ${ }^{12,14,19}$ In the periplasm, ArnT (PmrK) then transfers Ara4N from BP-Ara4N to lipid A. ${ }^{20}$

Limitations in procuring and detecting native BP-linked substrates have hindered characterization of enzymes involved in lipid A modifications. Recently, our group demonstrated the utility of fluorescent bactoprenyl phosphate to rapidly investigate the activity and specificity of bacterial glycosyl-

Received: July 28, 2021

Published: September 20, 2021 


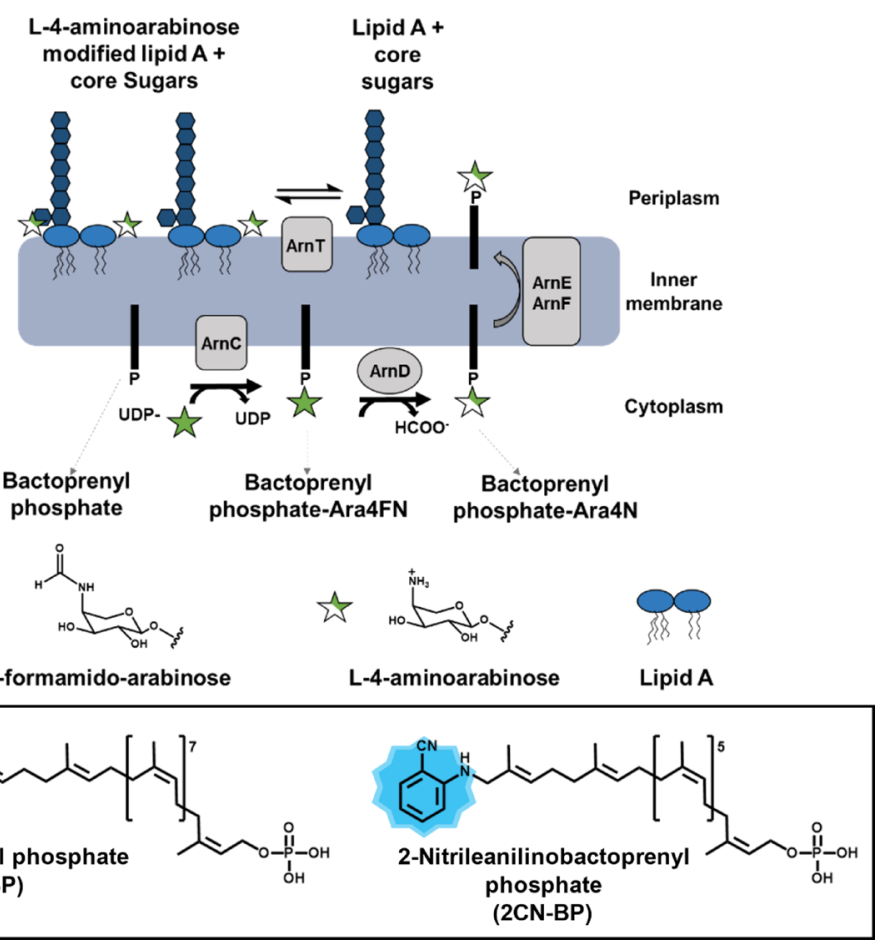

Figure 1. Biosynthetic pathway of lipid A modification with L-4-aminoarabinose in E. coli. Fluorescently labeled BP (2CN-BP) was used to probe endogenous enzyme activity within E. coli membrane fractions.
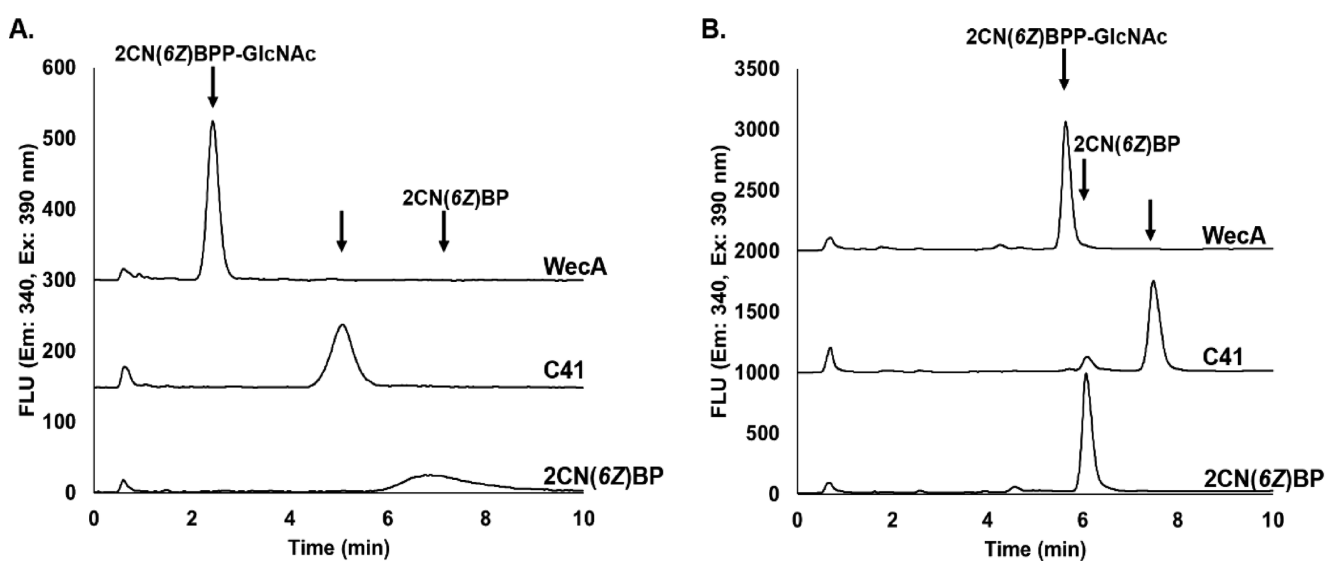

Figure 2. Wild-type C41(DE3) cell envelope fraction catalyzes the modification of 2CN(6Z)BP. (A) RP-HPLC (condition A) analysis of the WecA C41(DE3) membrane fraction incubated with $5 \mu \mathrm{M} 2 \mathrm{CN}(6 Z) \mathrm{BP}$ and $100 \mu \mathrm{M}$ UDP-GlcNAc compared to a C41(DE3) membrane fraction incubated with $5 \mu \mathrm{M} 2 \mathrm{CN}(6 \mathrm{Z}) \mathrm{BP}$ and no nucleotide-linked sugar. Each reaction contained $0.5 \mathrm{mg} / \mathrm{mL}$ (total protein) of the membrane fraction. The control was $5 \mu \mathrm{M} 2 \mathrm{CN}(6 Z) \mathrm{BP}$ input alone. Crude reactions were monitored with fluorescence detection and offset by 150 FLU increments. (B) RP-HPLC (condition B) analysis of reactions described in (A). Crude reactions were monitored with fluorescence detection and offset by 1000 FLU increments.

transferases including several enzymes within the initiating phospho-glycosyltransferase (PGT) protein family. ${ }^{21-23} \mathrm{Im}$ portantly, we found that the initiating PGT WecA from E. coli, which is responsible for appending GlcNAc-phosphate (GlcNAc-P) to BP, was present in cell envelope fractions in high enough quantities without overexpression to catalyze exogenous BP modification. In this report, we focused our efforts on determining whether these fluorescent probes could be used to characterize additional important endogenous proteins within the bacterial cell envelope, such as those required for polymyxin resistance.

\section{RESULTS}

Utilization of $2 \mathrm{CN}-\mathrm{BP}$ by $E$. coli Cell Envelope Fractions. In our previous analysis of PGT enzyme activity, we consistently observed that upon incubation of fluorescent 2nitrileanilinobactoprenyl phosphate (2CN-BP) with membrane fractions prepared from B-strain E. coli, an unidentified fluorescent product was formed. ${ }^{21}$ The presumed modified 2CN-BP was formed without the addition of nucleotide-linked sugar (NDP-sugar), which suggested that the donor substrate for the reaction was contained within the membrane fraction. In addition, the formation of this product was considerably lower and in some cases undetectable when a PGT (e.g., WecA) and its NDP-sugar substrate were added to the reactions exogenously to compete for available 2CN-BP (Figure 2). ${ }^{21}$ RP-HPLC analysis 
A.

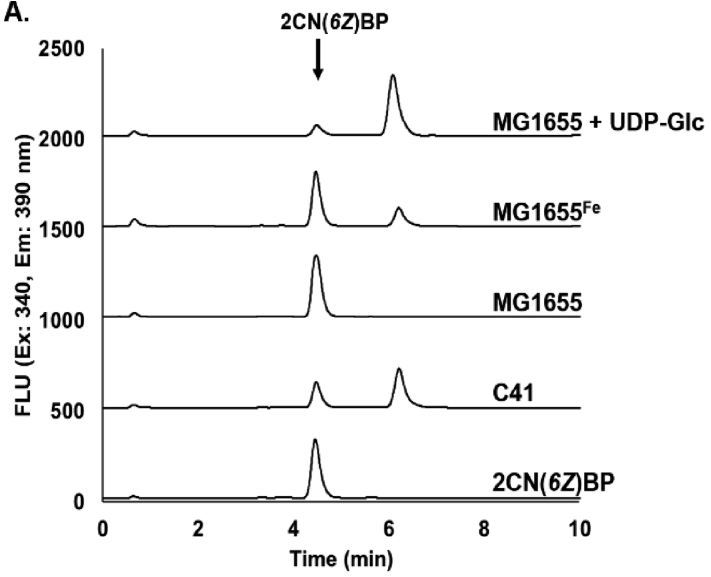

B.

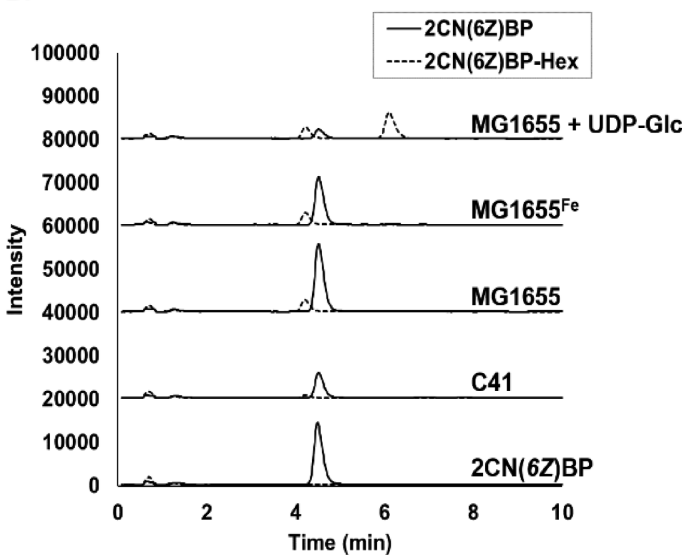

Figure 3. MG1655 membrane fraction prepared from cells cultured in the presence of $\mathrm{Fe}^{3+}$ utilize $2 \mathrm{CN}$-BP without the addition of nucleotide-linked sugar. (A) RP-HPLC analysis (Condition B) of crude reactions containing $5 \mu \mathrm{M} 2 \mathrm{CN}(6 \mathrm{Z}) \mathrm{BP}$ and $0.5 \mathrm{mg} / \mathrm{mL}$ (total protein) of membrane fractions prepared from E. coli C41(DE3) or MG1655. Crude reactions were monitored with fluorescence detection and offset by 500 FLU increments. (B) ESILC-MS with SIM in negative ion mode of reactions described in Figure A. Chromatograms were offset by 15,000 intensity units. A non-fluorescent peak corresponding to the $[\mathrm{M}-\mathrm{H}]^{-}$ion of $2 \mathrm{CN}(6 \mathrm{Z}) \mathrm{BP}-\mathrm{Glc}$ appears at $4.2 \mathrm{~min}$ and is associated with membrane fraction alone (data not shown). Control reactions contained $5 \mu \mathrm{M} 2 \mathrm{CN}-\mathrm{BP}$ alone.

A.

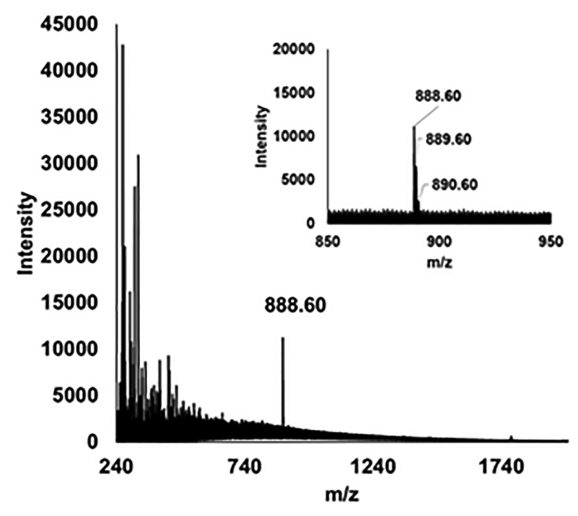

B.

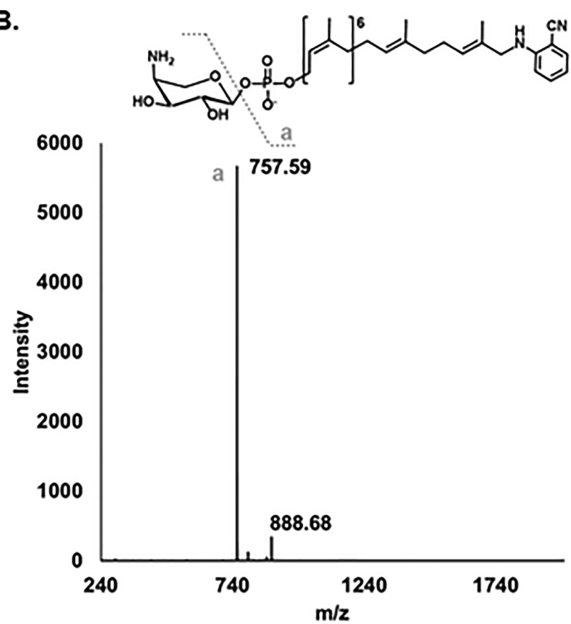

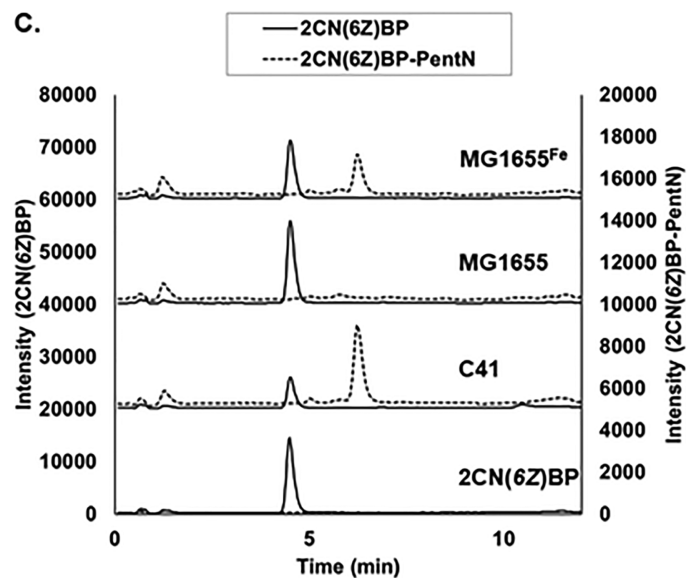

Figure 4. MS and MS/MS analysis of the unidentified product indicated an $m / z$ corresponding to $2 \mathrm{CN}(6 Z) \mathrm{BP}$-Ara4N. (A) ESI-MS of the unidentified product isolated from $\mathrm{C} 41$ (DE3) membrane fraction reactions with $2 \mathrm{CN}(6 Z) \mathrm{BP}$. (B) MS/MS analysis of the unidentified product. (C) ESI-LC-MS analysis (condition B) of crude reactions containing $5 \mu \mathrm{M} 2 \mathrm{CN}(6 Z) \mathrm{BP}$ and $0.5 \mathrm{mg} / \mathrm{mL}$ of the membrane fraction with SIM in negative ion mode. Chromatograms were offset by $20,000(2 \mathrm{CN}(6 \mathrm{Z}) \mathrm{BP})$ or $5000(2 \mathrm{CN}(6 \mathrm{Z}) \mathrm{BP}$-Ara4N) intensity units. Control reactions consisted of $5 \mu \mathrm{M}$ 2CN-BP alone.

of C41(DE3) membrane fraction reactions exempt of NDPsugar demonstrated that $0.5 \mathrm{mg} / \mathrm{mL}$ (total protein concen- tration) of the membrane fraction consumed approximately up to $100 \mathrm{pmol}$ of $2 \mathrm{CN}(6 Z) \mathrm{BP}$ (six isoprenes in the $\mathrm{Z}$ - 
configuration) (Figure S1). As a vehicle control, we found that product formation was not impacted by the presence of DMSO (up to $12 \%$ ) (Figure S1).

Notably, the retention time of this product on a conventional C18 column (Agilent Zorbax) with an ammonium bicarbonate/ n-propanol mobile phase (condition A) was intermediate to 2CN-BP and 2CN-BPP-GlcNAc, as evidenced by the $2.7 \mathrm{~min}$ difference in retention time when compared to the product of WecA (Figure 2A). ${ }^{21}$ However, using a high $\mathrm{pH}$-resistant $\mathrm{C} 18$ column (Waters XBridge) with an ammonium hydroxide/ $n$ propanol mobile phase (condition $\mathrm{B}$ ), the retention time of the unidentified product was greater than both $2 \mathrm{CN}-\mathrm{BP}$ and $2 \mathrm{CN}$ BPP-GlcNAc (Figure 2B). The chromatographic behavior of the unidentified product under both described conditions was comparable to a $2 \mathrm{CN}-\mathrm{BP}$-monosaccharide that we have observed during our investigation of another lipid A modification system (unpublished data), suggesting that the unidentified product, too, could be a polyisoprenoid monophosphate-linked sugar.

In support of this, Trent et al. demonstrated that B-strain $E$. coli such as $\mathrm{C} 41(\mathrm{DE} 3)$ appear to be inherently resistant to polymyxin and modify lipid A with Ara4N. ${ }^{24}$ Since lipid A modification systems are characterized by the requirement of a $\mathrm{BP}$-glycose donor, we viewed this as a possible source of a $2 \mathrm{CN}$ BP-monosaccharide (reviewed by Mann and Whitfield). ${ }^{25}$ Lipid A modification and expression of the arn operon ( $\operatorname{arn} B C A D$ $T E F)$ in $E$. coli has previously been attributed to the activation of the PmrA/B two-component regulatory system, including constitutively activating mutations in $p m r A$ or $p m r B .^{1,26-29}$ Unlike B-strains, K-strains do not modify lipid A with Ara4N and are thus sensitive to polymyxin unless induced by various environmental cues such as exposure to $\mathrm{Fe}^{3+}$ or metavanadate. ${ }^{7,30-33}$ Therefore, if the unidentified product was associated with Ara4N lipid A modification, no such modification of $2 \mathrm{CN}$ $\mathrm{BP}$ should occur with a membrane fraction prepared from a polymyxin-sensitive K-12 strain such as MG1655 grown under standard conditions, but perhaps we could induce this modification by culturing in arn-inducing conditions. ${ }^{20}$

To test this, we prepared two separate membrane fractions of the E. coli K-strain MG1655, the first prepared from cells cultured in LB and the second prepared from cells cultured in LB supplemented with $200 \mu \mathrm{M} \mathrm{Fe}^{3+}$. When $2 \mathrm{CN}-\mathrm{BP}$ was incubated with a membrane fraction prepared from MG1655 cells cultured in standard conditions, no product was formed (Figure 3A). However, when compared to the product of the C41(DE3) membrane fraction, a new product with an identical retention time was formed only by MG1655 membrane fraction prepared from cells cultured with $\mathrm{Fe}^{3+}$ (Figure 3A). These results indicated that the formation of this product could be induced by preparing membrane fractions from cells cultured with $\mathrm{Fe}^{3+}$ and that it is likely associated with Ara $4 \mathrm{~N}$ lipid A modification. Additionally, we noted that a new product was formed by the MG1655 membrane fraction (cultured without $\mathrm{Fe}^{3+}$ ) when incubated with UDP-glucose (Figure 3A). This product possessed a similar retention time $(6.07 \mathrm{~min})$ to that of the unknown product $(6.20 \mathrm{~min})$ and an $\mathrm{m} / z$ corresponding to the $[\mathrm{M}-\mathrm{H}]^{-}$ion of a $2 \mathrm{CN}-\mathrm{BP}-$ hexose as evidenced by ESI-LC-MS with selected ion monitoring (SIM) in negative ion mode (Figure 3B). Of the known possible gene products in E. coli that may append glucose to $2 \mathrm{CN}-\mathrm{BP}$, we attributed this activity to the phage-encoded glucosyltransferase $\mathrm{YfdH}$ (GtrB), which is not present in B-strains. ${ }^{34,35}$
To aid in the identification of the unknown product from C41(DE3) membrane fraction reactions, we prepared a reaction containing the C41(DE3) membrane fraction and $100 \mathrm{nmol}$ $2 \mathrm{CN}-\mathrm{BP}$ that was subsequently separated and isolated via RPHPLC. Analysis of the unidentified product with ESI-MS in negative ion mode indicated a predominant ion with an $\mathrm{m} / z$ of 888.60 , which corresponds to a predicted $[\mathrm{M}-\mathrm{H}]^{-} \mathrm{m} / \mathrm{z}$ of $2 \mathrm{CN}(6 Z) B P-A r a 4 N$ (888.57) (Figure 4A). Upon collisioninduced fragmentation, we observed an $m / z$ of 757.59 , which is consistent with the $[\mathrm{M}-\mathrm{H}]^{-}$ion of the fluorescent $2 \mathrm{CN}(6 \mathrm{Z}) \mathrm{BP}$ (expected $m / z 757.51$ ), and a loss of an Ara4N unit (Figure 4B). We then used ESI-LC-MS with SIM in negative ion mode to evaluate crude membrane fraction reactions for 2CN-BP-Ara4N (2CN-BP-PentN) (Figure 4C). As expected, the MG1655 membrane fraction produced the purported 2CN-BP-Ara $4 \mathrm{~N}$ product only when cells were cultured in the presence of $\mathrm{Fe}^{3+}$. These results demonstrated that the unidentified product was likely a modification of $2 \mathrm{CN}-\mathrm{BP}$ with Ara $4 \mathrm{~N}$ or another modification with an identical mass.

Membrane-Bound Enzymes in Ara4N Lipid a Modification Pathway Contribute to the Membrane FractionMediated Formation of 2CN-BP-Ara4N. We envisioned two possibilities as the source of the membrane fraction-mediated Ara $4 \mathrm{~N}$ modification of $2 \mathrm{CN}-\mathrm{BP}$ : (1) membrane-bound ArnC transfers Ara4FN to $2 \mathrm{CN}-\mathrm{BP}$ and is subsequently deformylated by membrane-associated ArnD or (2) membrane-bound ArnT transfers Ara4N from either native BP-Ara4N or LPS-Ara4N to 2CN-BP (Figure 5). To evaluate each of these possibilities, we

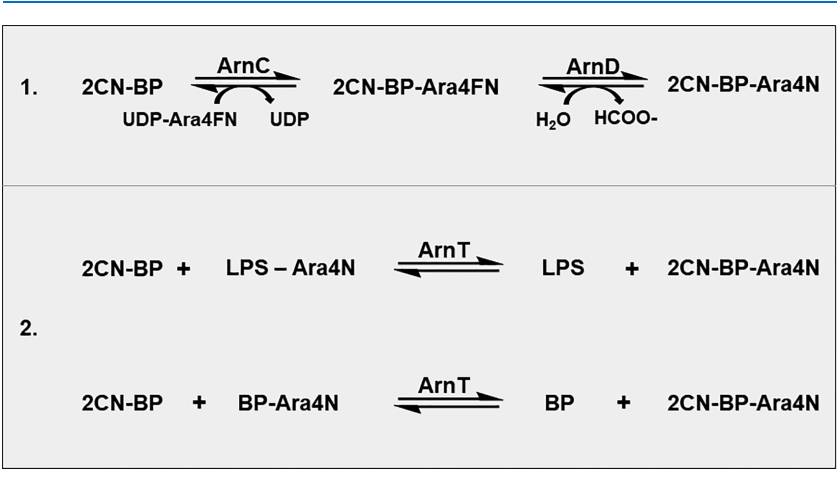

Figure 5. Schematic of potential sources of $2 \mathrm{CN}-\mathrm{BP}$ modification with Ara4N.

created deletions of $a r n C$ and $a r n T$ in $\mathrm{C} 41$ (DE3). We reasoned that a non-polar deletion of arnC would not impede the formation of UDP-Ara4FN but would preclude the synthesis of endogenous BP-Ara4N and LPS-Ara4N. Thus, we expected that deleting $\operatorname{arn} C$ would abolish the production of $2 \mathrm{CN}-\mathrm{BP}-\mathrm{Ara} 4 \mathrm{~N}$ in membrane fraction reactions by preventing transfer from ArnC or ArnT. In the same regard, we anticipated that if ArnCD was responsible for mediating the transfer of Ara $4 \mathrm{~N}$ to $2 \mathrm{CN}-\mathrm{BP}$, the deletion of $\operatorname{arn} T$ would not affect the production of $2 \mathrm{CN}-\mathrm{BP}$ Ara4N but would preclude the formation of LPS-Ara4N.

To evaluate the activity of $\Delta a r n T$ and $\Delta a r n C$ mutant membrane fractions, we prepared reactions containing either a wild-type or mutant membrane fraction incubated with $2 \mathrm{CN}-\mathrm{BP}$ and analyzed the crude reactions for $2 \mathrm{CN}-\mathrm{BP}$-Ara $4 \mathrm{~N}$ using $\mathrm{RP}$ HPLC (condition A) (Figure 6). As predicted, RP-HPLC analysis of the $\Delta a r n C$ membrane fraction with $2 \mathrm{CN}$-BP did not demonstrate the formation of 2CN-BP-Ara4N. Extrachromosomal complementation of $\operatorname{arn} C$ with a high copy number 

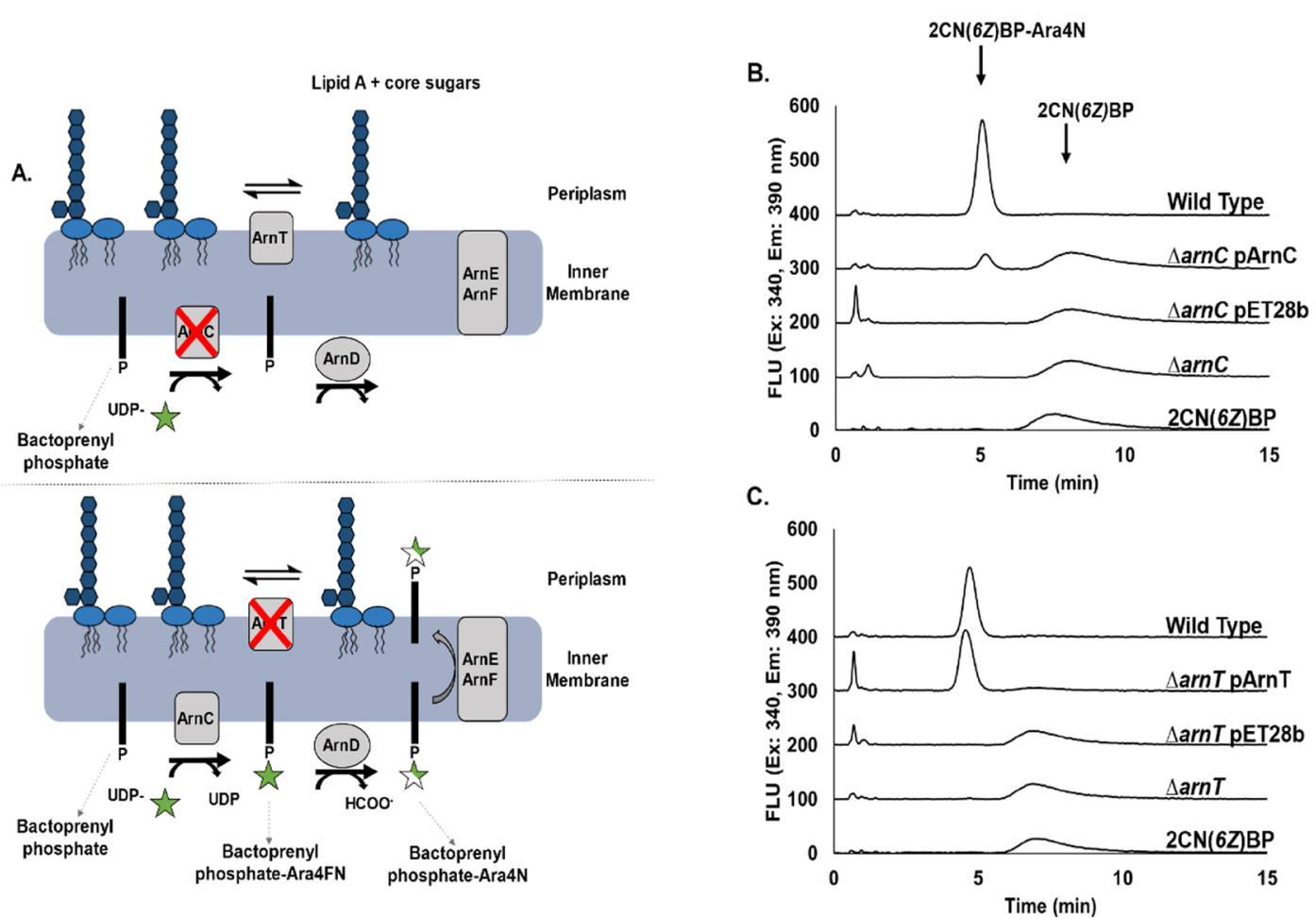

Figure 6. Deletion of $\operatorname{arnC}$ or $\operatorname{arnT}$ in $\mathrm{C} 41(\mathrm{DE} 3)$ abolishes cell envelope production of $2 \mathrm{CN}$-BP-Ara4N. Reactions with 2CN(6Z)BP and membrane fractions prepared from wild-type or mutant C41(DE3) were separated by RP-HPLC (condition A) and evaluated for product formation with fluorescence detection. Chromatograms were offset by $100 \mathrm{FLU}$ increments. (A) Schematic of potentially available intermediates in each mutant membrane fraction. (B) $\Delta a r n C$ C41(DE3) membrane fraction compared to wild-type membrane fraction incubated with $2 \mathrm{CN}(6 \mathrm{Z}) \mathrm{BP}$. (C) $\Delta a r n T$ $\mathrm{C} 41(\mathrm{DE} 3)$ membrane fraction compared to wild-type membrane fraction incubated with $2 \mathrm{CN}(6 \mathrm{Z}) \mathrm{BP}$.

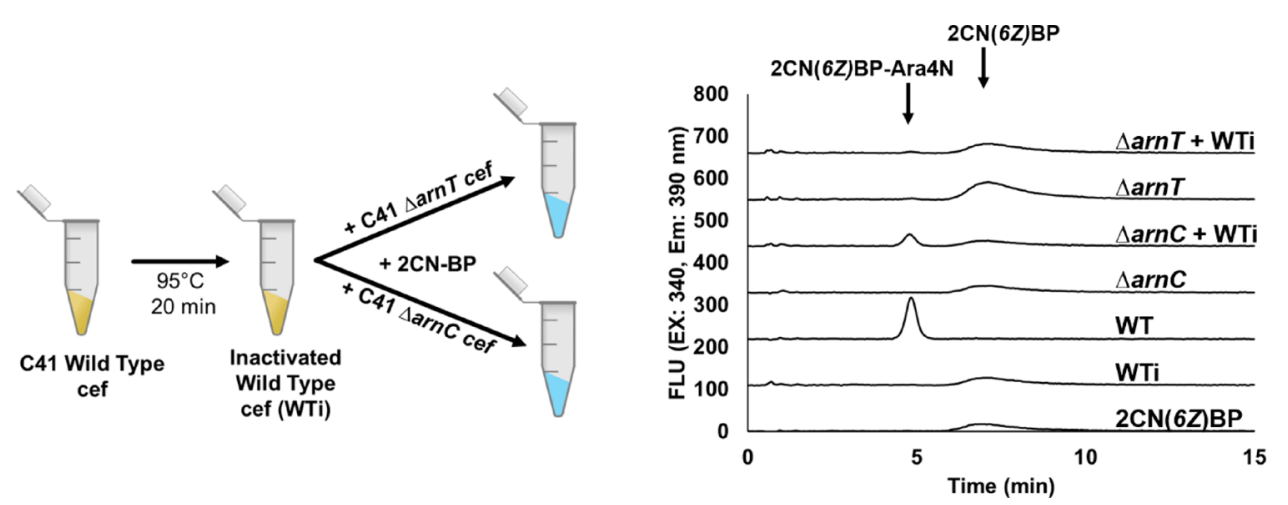

Figure 7. arn T, but not $\operatorname{arnC}$, is required for the modification of $2 \mathrm{CN}-\mathrm{BP}$ in the presence of an exogenous substrate. Mutant membrane fractions $(0.5$ $\mathrm{mg} / \mathrm{mL}$ ) were incubated with $5 \mu \mathrm{M} 2 \mathrm{CN}(6 \mathrm{Z}) \mathrm{BP}$ both with and without $0.5 \mathrm{mg} / \mathrm{mL}$ of the inactivated wild-type membrane fraction (WTi). Crude reactions were separated by RP-HPLC (condition A) and analyzed with fluorescence detection. Chromatograms are offset by 100 FLU increments.

plasmid partially restored the activity of $\Delta a r n C$ pArnC membrane fraction compared to the wild type. Interestingly, we found that the $\Delta a r n T$ membrane fraction also did not produce $2 \mathrm{CN}-\mathrm{BP}-\mathrm{Ara} 4 \mathrm{~N}$, suggesting that ArnT is required for the modification of exogenous 2CN-BP with Ara $4 \mathrm{~N}$ (Figure 6B). Complementation of $\operatorname{arn} T$ restored that activity, while expression of an empty plasmid control in either mutant did not (Figure 6C). To confirm expression of arnC and arnT in our complementation analyses, we confirmed the presence of 6XHis-tagged ArnC and ArnT in membrane fractions with an anti-His Western blot (Figure S2). These results further support our hypothesis that Arn enzymes in the membrane fraction are involved in this new product formation and that the modification is indeed Ara4N (i.e., not another modification with an identical mass).

Modification of 2CN-BP by $\Delta$ arnC Membrane Fraction Is Facilitated by the Addition of Exogenous Substrate. We next evaluated potential sources of Ara4N modification by supplying an exogenous donor substrate in the form of a heatinactivated wild-type membrane fraction to either the $\Delta a r n C$ or $\Delta a r n T$ mutant membrane fraction (Figure 7 ). The inactivated wild-type membrane fraction would harbor the donor substrate, but the proteins (ArnC or ArnT) are inactive. Supplementation of the exogenous substrate to a reaction containing the $\Delta a r n C$ membrane fraction would enable us to evaluate the activity of ArnT. Similarly, by using the $\Delta a r n T$ membrane fraction, we could then evaluate the activity of ArnC. To do so, each active 
membrane fraction was incubated with or without equivalent quantities of inactivated wild-type membrane fraction. Wildtype or inactive wild-type membrane fractions with $2 \mathrm{CN}-\mathrm{BP}$ were used as controls. When reactions containing the $2 \mathrm{CN}-\mathrm{BP}$ and $\Delta a r n C$ membrane fraction were supplemented with the inactive membrane fraction, a new product was formed. The retention time of this new product corresponded to the same retention time as $2 \mathrm{CN}-\mathrm{BP}-\mathrm{Ara} 4 \mathrm{~N}$ ( $4.83 \mathrm{~min}$, condition A) produced by the wild-type membrane fraction. No such product was formed under these conditions with the $\Delta a r n T$ membrane fraction. These results suggest that ArnT is responsible for transferring Ara4N to 2CN-BP.

To address whether native BP-Ara4N could serve as the Ara4N donor substrate for the ArnT-catalyzed formation of 2CN-BP-Ara4N, we first determined whether native BP-Ara4N would accumulate in the $\mathrm{C} 41(\mathrm{DE} 3)$ strain. Accumulation and detection of BP-Ara4N have been well established in polymyxinresistant E. coli and Salmonella enterica. ${ }^{19,24}$ These methods typically employ lipid extraction from cell lysates followed by MALDI-MS or ESI-MS. ${ }^{19,24,34}$ Similarly, we used ESI-LC-MS to detect BP, BP-Ara4FN, and BP-Ara4N in total lipid extracts of $E$. coli cell lysates. ${ }^{36}$ Using SIM in negative ion mode, we were able to reliably detect endogenous $\mathrm{BP}\left([\mathrm{M}-\mathrm{H}]^{-} m / z 845.7\right)$ in wildtype C41(DE3) and mutant lipid extracts. BP-Ara4N (BPPentN, $[\mathrm{M}-\mathrm{H}]^{-} \mathrm{m} / z$ 976.7) was detected only in wild-type C41(DE3) and $\Delta a r n T$ C41(DE3) but not in $\Delta$ arnC C41(DE3) (Figure 8), a result that is corroborated by a previous characterization of BP-Ara $4 \mathrm{~N}$ biosynthesis. ${ }^{14,24}$ Interestingly, triplicate analysis of equally prepared lipids demonstrated a consistent 2.5-fold increase in the abundance of BP in lipids prepared from $\Delta a r n C$ C41(DE3).
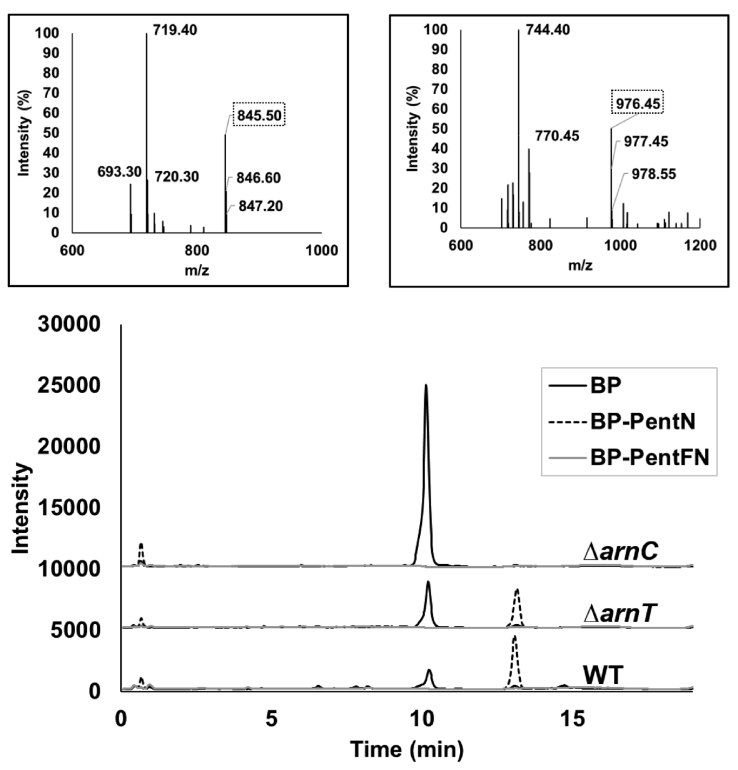

Figure 8. ESI-LC-MS with SIM of accumulated BP and BP-Ara4N in wild-type and mutant C41(DE3) lipids. Total lipids prepared from wild-type, $\Delta a r n C$, or $\Delta a r n T C 41(D E 3)$ cells were analyzed with ESILC-MS (condition B) and SIM in negative ion mode. Chromatograms were offset by 5000 intensity units. The left inset depicts the mass spectrum obtained from the total ion scan from 9.8 to 10.2 min in lipids prepared from the $\Delta a r n C$ C41(DE3) mutant. Right inset depicts the mass spectrum obtained from the total ion scan from 13.0 to $13.4 \mathrm{~min}$ in lipids prepared from wild-type C41(DE3). Signals observed in the $700-800 \mathrm{~m} / z$ range likely correspond to phospholipids.
Complementation of the $\Delta a r n C$ mutant with a high copy number plasmid restored the accumulation of BP-Ara $4 \mathrm{~N}$ but only to a minor extent when compared to the wild type (Figure S3). This result is akin to the previous complementation analysis with RP-HPLC, in which full conversion of $2 \mathrm{CN}-\mathrm{BP}$ was not achieved by complementation of the $\Delta a r n C$ mutant (Figure 6). Complementation of the $\Delta a r n T$ mutant did not significantly alter the intensity of either $\mathrm{BP}$ or $\mathrm{BP}-\mathrm{Ara} 4 \mathrm{~N}$ relative to the wild type. A signal corresponding to BP-Ara4FN was not detected in either wild-type or mutant lipid extracts (BP-PentFN, [M$\mathrm{MH}]^{-}$1004.71). However, we were able to detect BP-Ara4FN in lysates prepared from the complemented arnC mutant (Figure S3).

Based on the analysis of native BP and BP-Ara4N in C41(DE3) lipid extracts, the $\Delta a r n T$ membrane fraction would likely harbor both BP and BP-Ara4N but not lipopolysaccharide (LPS)-Ara $4 \mathrm{~N} .^{24}$ To rule out the possibility of native BP-Ara $4 \mathrm{~N}$ as the donor substrate for the modification of $2 \mathrm{CN}-\mathrm{BP}$, we then prepared the inactivated $\Delta a r n T$ membrane fraction and supplied it to wild-type and mutant membrane fractions as a source of BP-Ara4N. HPLC analysis of crude reactions did not indicate the production of $2 \mathrm{CN}-\mathrm{BP}-\mathrm{Ara} 4 \mathrm{~N}$ when the $\Delta$ arnC membrane fraction was incubated with the inactivated $\Delta a r n T$ membrane fraction (Figure S4). These results suggest that endogenous BP-Ara4N does not supply the Ara4N donor for $2 \mathrm{CN}-\mathrm{BP}$ modification and collectively indicate that the aberrant production of $2 \mathrm{CN}-\mathrm{BP}-\mathrm{Ara} 4 \mathrm{~N}$ is mediated through the reverse reaction of ArnT, in which Ara4N is transferred from LPSAra4N to exogenously supplied 2CN-BP.

ArnT-Catalyzed Reverse Transfer of Ara4N Occurs with Fluorescent and Native BP. To evaluate whether LPS could serve as an Ara4N donor substrate, a fraction of LPS was prepared from wild-type C41(DE3) that was expected to contain Ara4N-modified LPS. Using a shortened procedure for lipid A isolation, C41(DE3) cells were lysed in a single-phase Bligh and Dyer solution and crude LPS was collected as an insoluble precipitate. ${ }^{36,37}$ Samples prepared using this method are expected to be relatively free of any BP and BP-linked intermediates, as phospholipids and prenyl lipids are extracted in the soluble fraction (see Experimental Methods). ${ }^{37}$ A sample of isolated material was visualized with SDS-PAGE, which showed minimal contamination and a banding pattern consistent with the anticipated truncated LPS of B-strain E. coli (Figure S5). ${ }^{38,39}$ The isolated material was then added to reactions containing $2 \mathrm{CN}-\mathrm{BP}$ and wild-type or mutant membrane fractions (Figure 9A). In this analysis, we found that only the $\Delta a r n C$ membrane fraction produced $2 \mathrm{CN}-\mathrm{BP}-\mathrm{Ara} 4 \mathrm{~N}$ when incubated with isolated LPS fractions. Additionally, a consistent, linear increase in the turnover of $2 \mathrm{CN}-\mathrm{BP}$ was observed in reactions containing the $\Delta a r n C$ membrane fraction when the amount of LPS (approximately $20 \mu \mathrm{g}$ ) was increased up to 4 -fold (Figure 9B and Figure S6).

Based on our analysis of BP and BP-Ara4N levels in wild-type and mutant C41(DE3) cell lysates (Figure 8), we determined that $\Delta a r n C$ cells have an abundance of available BP. To ensure that the transfer of Ara4N from LPS-Ara4N also occurred with native $\mathrm{BP}$ and not just $2 \mathrm{CN}-\mathrm{BP}$, we prepared reactions containing the $\Delta a r n C$ membrane fraction supplemented with LPS, in which the $\Delta a r n C$ membrane fraction would serve as a source of both BP and ArnT (Figure 10A). Lipids were then extracted with $n$-butanol, dried under vacuum, and resuspended in $n$-propanol/10 $\mathrm{mM}$ ammonium hydroxide prior to ESI-LCMS analysis. As anticipated, BP-Ara4N was observed only when 
A.

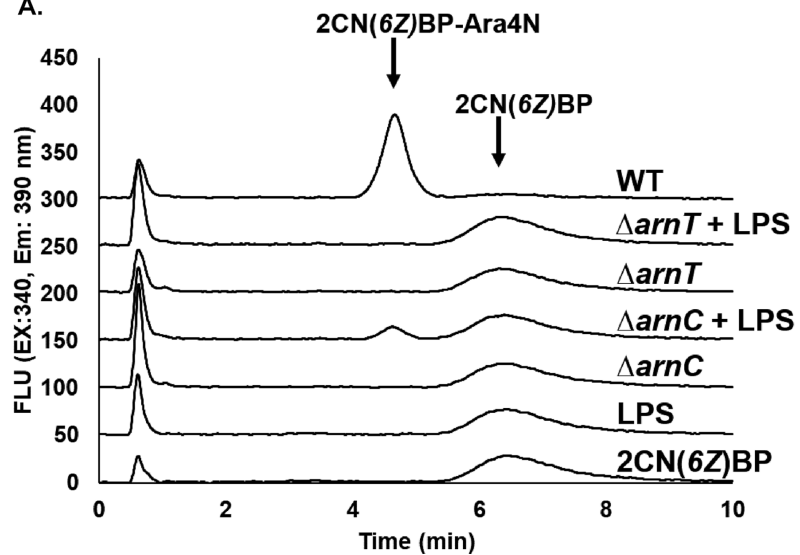

B.

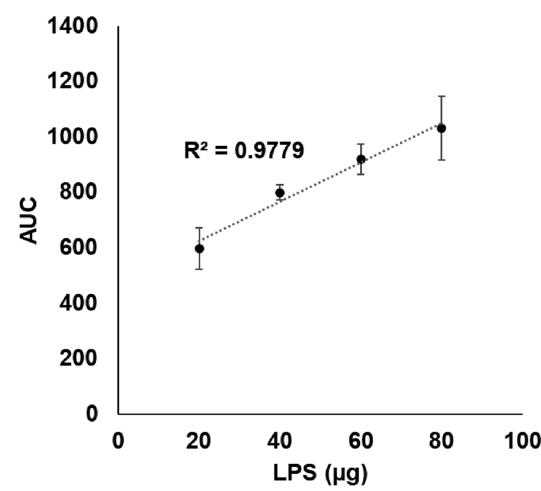

Figure 9. $\triangle a r n C$ C41(DE3) membrane fraction catalyzes the conversion of $2 \mathrm{CN}-\mathrm{BP}$ in the presence of wild-type LPS. (A) Mutant membrane fractions $(0.5 \mathrm{mg} / \mathrm{mL}$ total protein) were incubated with $5 \mu \mathrm{M} 2 \mathrm{CN}(6 \mathrm{Z}) \mathrm{BP}$ both with and without $20 \mu \mathrm{g}$ of isolated wild-type LPS and analyzed by RP-HPLC (condition A). Chromatograms were offset by 50 FLU increments. (B) Reactions were supplemented with incremental amounts of LPS $(20-80 \mu \mathrm{g})$, which increased the turnover of $2 \mathrm{CN}(6 \mathrm{Z}) \mathrm{BP}$ linearly. Turnover of $2 \mathrm{CN}(6 \mathrm{Z}) \mathrm{BP}$ was determined by measuring the peak area associated with $2 \mathrm{CN}(6 \mathrm{Z}) \mathrm{BP}-\mathrm{Ara} 4 \mathrm{~N}(4.8 \mathrm{~min})$. Error bars represent the standard deviation of triplicate experiments.

A.

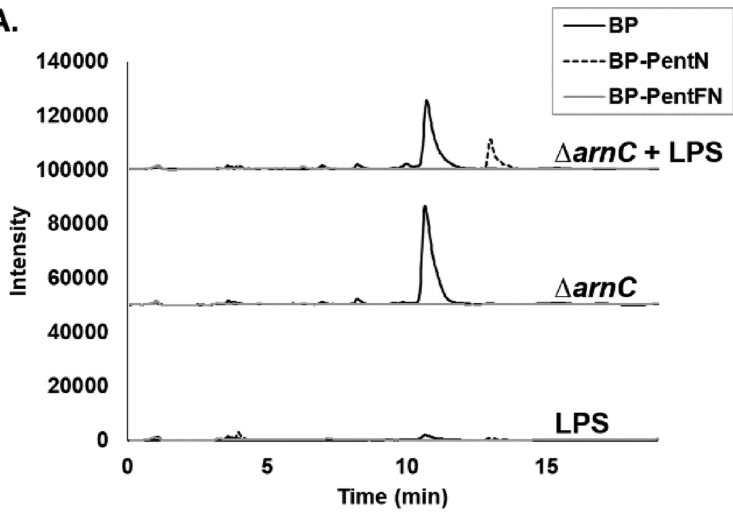

B.

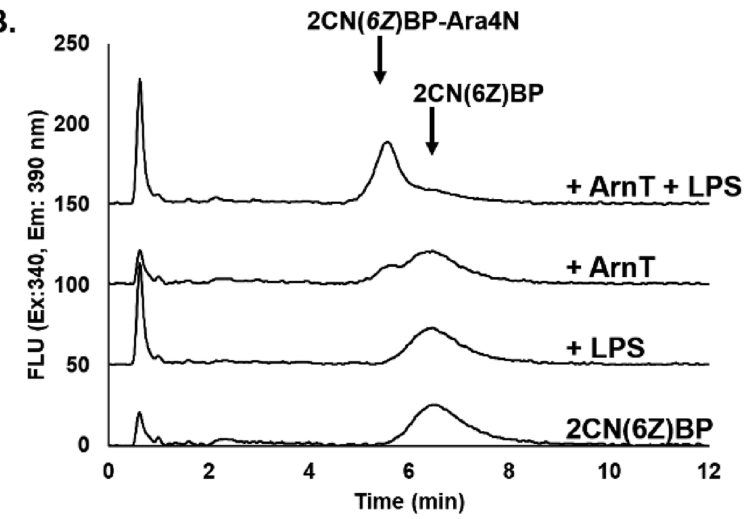

Figure 10. Cell envelope fraction prepared from $\Delta$ arnC C41(DE3) produces BP-Ara4N when incubated with LPS. (A) The $\triangle a r n C$ C41(DE3) membrane fraction $(0.5 \mathrm{mg} / \mathrm{mL}$ total protein) was incubated in buffered reaction conditions with approximately $50 \mu \mathrm{g}$ of purified LPS prepared from wild-type C41(DE3) cells. The $\triangle a r n C$ membrane fraction or LPS alone were used as controls. Crude reactions were monitored for the presence of BPAra4N with ESI-LC-MS and SIM (condition B). Chromatograms were offset by 50,000 intensity units. (B) Purified ArnT was incubated with $2 \mathrm{CN}(6 \mathrm{Z}) \mathrm{BP}$ both with and without $20 \mu \mathrm{g}$ LPS. Crude reactions were monitored with RP-HPLC (condition A) and fluorescence detection. Chromatograms were offset by 50 FLU increments.

the $\Delta a r n C$ membrane fraction was incubated with LPS but not in the $\Delta a r n C$ membrane fraction or LPS alone.

To demonstrate that reverse transfer is catalyzed by ArnT and not another enzyme within the membrane fraction, ArnT bearing a 6xHis-tag was overproduced in C41(DE3) and solubilized as described in the Experimental Methods (Figure S7). ${ }^{40}$ To evaluate the activity of purified ArnT, we incubated ArnT and 2CN-BP both with and without LPS and monitored for 2CN-BP-Ara4N (Figure 10B). RP-HPLC analysis of these reactions indicated that purified ArnT without added LPS catalyzed the conversion of $2 \mathrm{CN}-\mathrm{BP}$, albeit full-turnover was not achieved. This result was not surprising since isolated proteins are typically contaminated with LPS. ${ }^{41}$ When purified LPS from C41(DE3) was added to ArnT reactions, 2CN-BP was nearly consumed as indicated by the increase in $2 \mathrm{CN}-\mathrm{BP}-\mathrm{Ara} 4 \mathrm{~N}$ and reduction in $2 \mathrm{CN}-\mathrm{BP}$.

Characterization of E. Coli ArnD with Native BPAra4FN Substrate. Based on the utility of ESI-LC-MS methods described above to detect native BP-linked intermediates, we next sought to apply these methods to characterize the function of ArnD with its native substrate, BP-Ara4FN. In similar lipid A modification pathways, deacetylation or deformylation is required to finalize the transfer of cationic glycoses to lipid A (reviewed by Mann and Whitfield). ${ }^{25}$ Recent analysis of an ArnD homolog from Burkholderia cenocepacia with a synthetic analogue of BP-Ara4FN demonstrated ArnD deformylase activity. ${ }^{18}$ To bypass the need for syntheses of BP-Ara4FN or UDP-Ara4FN, we used a genetic approach to promote the accumulation of native BP-Ara4FN in E. coli, which could then be collected and used for functional assays in vitro. To do so, we created a $\Delta a r n D$ mutation in the K-12 MG1655 background and tested whether the accumulation of BP-Ara4FN could be promoted by culturing these cells in the presence of $\mathrm{Fe}^{3+}$. ESI-LC-MS analysis of total lipid extracts from wild-type MG1655 demonstrated a minor accumulation of BP-Ara4N when cells were cultured in the presence of $\mathrm{Fe}^{3+}$ (Figure 11A). Accordingly, analysis of lipid extracts from $\Delta$ arnD MG1655 cells demonstrated that BP-Ara4FN was only detected when cells were grown in the presence of $\mathrm{Fe}^{3+}$ (Figure 11,BA).

Using lipid extracts of $\Delta a r n D$ MG1655 cells containing BPAra4FN, we then assessed the deformylase activity of $E$. coli ArnD. To express and purify $A r n D$, we used a purification 
A.

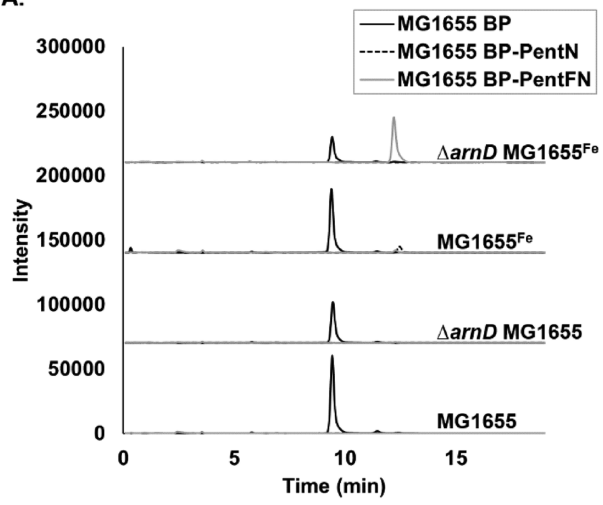

B.
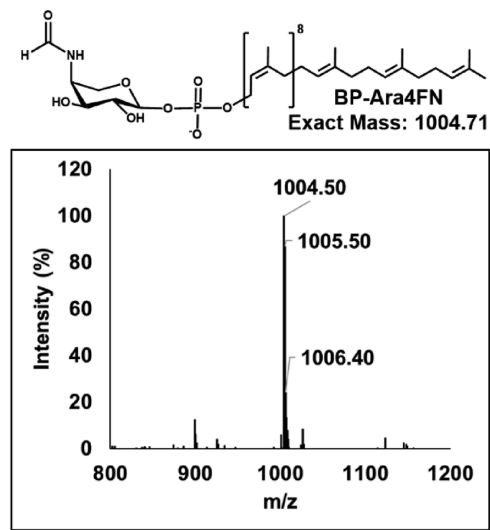

c.

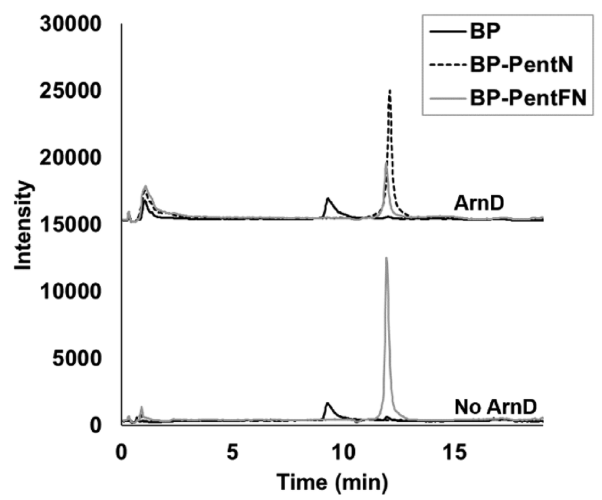

Figure 11. Induced accumulation of native BP-Ara4FN and deformylation of BP-Ara4FN by E. coli ArnD. (A) Lipids prepared from MG1655 and $\Delta$ arnD MG1655 cells cultured in LB with or without $\mathrm{Fe}^{3+}$ were analyzed with ESI-LC-MS (condition B) with SIM in negative ion mode for BP, BPPentN, and BP-PentFN ([M-H $]^{-} \mathrm{m} / z$ 1004.7). (B) Mass spectrum obtained from the total ion scan of $\Delta a r n D$ MG1655 $5^{\mathrm{Fe}}$ from 12.0 to $12.6 \mathrm{~min}(\mathrm{C})$ Reactions containing lipids prepared from MG1655 $\Delta$ arnD cultured with $\mathrm{Fe}^{3+}$ and $0.05 \mathrm{mg} / \mathrm{mL}$ ArnD were monitored for BP-Ara4N (BP-PentN) with SIM. Control reactions contained lipids in reaction buffer with no ArnD.

procedure recently reported by Adak et al. ${ }^{18}$ The presence of ArnD was confirmed with SDS-PAGE and anti-His Western blotting (Figure S8). Purified ArnD was then incubated in buffered reactions with lipids prepared from MG1655 $\Delta a r n D$ cells cultured with $\mathrm{Fe}^{3+}$. Deformylase activity was monitored with ESI-LC-MS using SIM in negative ion mode and evidenced by the formation of BP-Ara4N (Figure 11).

\section{DISCUSSION}

Previously established methods for evaluating polyprenylphosphate glycosyltransferases have relied on the specific detection of radiolabeled glycoses. Here, we have highlighted additional polyisoprenoid-linked products that are formed due to the reversibility of these reactions and likely go undetected. In events of poor recombinant protein production or function, exogenously added isoprenoid substrate may be consumed by these reactions, significantly reducing the availability of BP and preventing glycosylation or detection of the intended product. On the other hand, we also note that the availability of BP glycose substrates is limited and that reverse reactions demonstrated here may be used to generate these substrates in vitro. As noted by Olagnon et al., new strategies for acquiring and evaluating polyisoprenyl-phosphate intermediates will address the lack of available substrates required for the rational design of inhibitors, as well as limitations associated with clarifying the function of enzymes involved in lipid A modifications with cationic glycoses. $^{42}$
Accordingly, this research directly addresses the deficit of polyisoprenoid substrates by demonstrating the utility of two efficient methods used to obtain both native and tagged BPglycoses. Specifically, we demonstrate the unique advantage of 2CN-BP used to selectively probe the activity of endogenous BP utilizing proteins within membrane fractions of both $\mathrm{K}$ - and $\mathrm{B}$ strains of E. coli. This method may also prove effective for the evaluation of other Gram-negative pathogens, particularly, without the need for gene overexpression and protein purification. Previously, such findings have enabled the characterization of early stages of bacterial glycan biosynthesis such as the enterobacterial common antigen in E. coli. ${ }^{43}$

Similarly, our methods revealed an unestablished activity of ArnT, for which prior characterization of the forward reaction has required the isolation of small quantities of native BP-Ara4N or the use of shorter, synthetically prepared Ara4N-linked isoprenoids. $^{24,42}$ Reverse catalysis of PGT enzymes, where UDP-sugar is formed from BPP-sugar in the presence of UMP, has been demonstrated in vitro with various initiating PGT and glycosyltransferase enzymes. ${ }^{44,45}$ Research has also been directed at harnessing these reactions to obtain complex NDP-linked sugars, akin to our generation of fluorescent BPlinked Ara $4 \mathrm{~N}$ here. ${ }^{46}$ We show that the reverse transfer of ArnT may be harnessed to provide ample fluorescent BP-Ara4N donor substrate for further analysis of ArnT activity in vitro.

It is interesting to consider whether reverse transfer of Ara4N from LPS to BP may occur in the cell. LPS transport from the 
inner membrane to the outer membrane requires an ATPbinding cassette $(\mathrm{ABC})$ transporter and a protein bridge to shuttle the large glycolipid through the periplasmic space to the outer leaflet of the outer membrane. ${ }^{47-49}$ Recently, Owens et al. demonstrated that ATP hydrolysis promotes LPS movement onto the protein bridge and prevents the backward transport of LPS, providing substantial evidence of unidirectional LPS transport. ${ }^{50}$ With the exception of reaction equilibriums at the periplasmic inner membrane, the ArnT-catalyzed reverse transfer of Ara4N to BP would require LPS to be translocated back to the periplasmic face of the inner membrane where ArnT is situated. ${ }^{20}$ We conclude that reverse transfer of Ara4N to BP after LPS has been modified and translocated to the outer membrane is unlikely. Additionally, in the cell, the rapid translocation of modified LPS to the outer membrane likely pushes the reaction forward. It is more likely that reverse transfer is an artifact of cell membrane fractionation. Nonetheless, this report reveals considerations that must be made during in vitro analyses of glycosyltransferases and substrate utilization, where this unfavored reaction may consume, as evidenced by our analyses, a large portion of exogenously added isoprenoid.

In addition to analyses with fluorescent BP, our methods enabled the rapid detection of native $\mathrm{BP}$ and $\mathrm{BP}$ intermediates in lipids collected from constitutive and $\mathrm{Fe}^{3+}$-induced polymyxinresistant E. coli. Considering the unlikely reversibility of the BPAra4N intermediate, we noted a consistent increase in the abundance of BP in C41(DE3) cells lacking arnC, which is likely the result of $\mathrm{BP}$ being relinquished from the lipid A modification pathway. ${ }^{14,51}$ We also note that the sequestration of BP through other pathways is associated with deformed cell shape, cell membrane permeability, and increased sensitivity to bile salts. ${ }^{51-53}$ Presumably, deleterious effects of an accumulated intermediate in the Arn pathway and the resultant sequestration of the vital BP precursor would make ArnT an ideal candidate for the development of inhibitors. ${ }^{11,54}$ ArnT inhibition could result in $\mathrm{BP}$ sequestration as $\mathrm{BP}-\mathrm{Ara} 4 \mathrm{~N}$ and simultaneously eliminate polymyxin resistance and sensitize CAMP-resistant bacteria to environmental or host-mediated stressors. Ultimately, the methods presented here will facilitate a more quantitative assessment of accumulated BP intermediates, BP expenditure, and sequestration in various culturing conditions and among various genotypes. Future research should be directed at characterizing and quantifying the effects of BP sequestration as an Arn intermediate.

\section{EXPERIMENTAL METHODS}

Materials and Bacterial Strains. The fluorescent $2 \mathrm{CN}$ (6Z)BP substrate was prepared as previously described (Ex: 340, Em: $390 \mathrm{~nm}){ }^{21,55}$ E. coli MG1655 was generously provided by the Young/Jorgenson Laboratory at the University of Arkansas for Medical Sciences. C41(DE3) was purchased from Novagen.

Cell Envelope Fractionation. To evaluate the activity of $E$. coli membrane proteins with the $2 \mathrm{CN}(6 Z) \mathrm{BP}$, we prepared membrane fractions from wild-type and mutant $E$. coli in both C41(DE3) and MG1655. Starter cultures were prepared from isolated colonies and incubated overnight at $37^{\circ} \mathrm{C}$. Cultures containing $250 \mathrm{~mL}$ of LB Miller broth were inoculated with a 1:1000 dilution of starter culture and incubated at $37^{\circ} \mathrm{C}$ at 220 rpm until an $\mathrm{OD}_{595}$ of $0.8-1.0$. Cells were then pelleted at 5000 $\mathrm{RCF}$ for $15 \mathrm{~min}$. Cell pellets were resuspended in $0.8 \% \mathrm{NaCl}$, pelleted at $5000 \mathrm{RCF}$ for $15 \mathrm{~min}$, and stored at $-80{ }^{\circ} \mathrm{C}$ for about 1 week prior to the preparation of the membrane fraction. To prepare membrane fractions, cells were resuspended in buffer A (50 mM Tris $\mathrm{pH} 8.0,300 \mathrm{mM} \mathrm{NaCl}$ ) and lysed with sonication (Fisher Sonic Dismembrator). Lysates were centrifuged at 5000 RCF for 20 min to remove unlysed cells and cellular debris. The supernatant was then spun at 100,000 RCF for $1 \mathrm{~h}$. The resulting pellets were resuspended in buffer B (50 mM Tris, $200 \mathrm{mM}$ $\mathrm{NaCl}$ ) and stored at $-80^{\circ} \mathrm{C}$ until use. The total protein content of membrane fractions was determined with a Bradford assay at $595 \mathrm{~nm}$ using bovine serum albumin (BSA) as a standard.

RP-HPLC. All RP-HPLC (condition A) was performed with an Agilent 1100 HPLC system equipped with a variable wavelength and fluorescence detector (FLD) using an Agilent Zorbax XBD-C18 column $(4.6 \mathrm{~mm} \times 50 \mathrm{~mm}, 3 \mu \mathrm{m}, 80 \AA)$. The mobile phase comprised $n$-propanol (solvent A) and $100 \mathrm{mM}$ ammonium bicarbonate (solvent B). Analysis occurred with an isocratic mobile phase consisting of $50 \%$ solvent $\mathrm{A} / 50 \%$ solvent $B$ at a flow rate of $1 \mathrm{~mL} / \mathrm{min}$. Injection quantities of the starting material $(2 \mathrm{CN}(6 Z) \mathrm{BP})$ were kept consistent at 100 pmol unless noted otherwise.

ESI-LC-MS. All ESI-LC-MS analysis (condition B) was performed with an Agilent 1260 Infinity II system equipped with a single quadrupole and fluorescence detector using a Waters XBridge Peptide BEH C18 column $(4.6 \mathrm{~mm} \times 50 \mathrm{~mm}$, $3.5 \mu \mathrm{m}, 300 \AA)$. The mobile phase comprised $n$-propanol (solvent $\mathrm{C}$ ) and $10 \mathrm{mM}$ ammonium hydroxide (solvent $\mathrm{D}$ ) with a flow rate of $1 \mathrm{~mL} / \mathrm{min}$. For all analyses, the column temperature was set to $30{ }^{\circ} \mathrm{C}$. MS parameters for each analysis included a nebulizer pressure of $50 \mathrm{psi}$, drying gas flow of $12.0 \mathrm{~L} /$ min, drying gas temperature of $350{ }^{\circ} \mathrm{C}$, and capillary voltage of $4000 \mathrm{~V}$. All analyses were performed in negative ion mode.

For analysis of native BP, BP-Ara4N, and BP-Ara4FN with ESI-LC-MS, each of the four channels analyzed three SIM ions and one scan from $400-1500 \mathrm{~m} / z$. Scan parameters included a fragmentation voltage 350 of $\mathrm{V}$, gain of 1.0, threshold of 150 , step size of 0.1 , and scan speed of $2600 \mathrm{u} / \mathrm{s}$. SIM parameters included a fragmentation voltage of $350 \mathrm{~V}$, gain of 1.0, and dwell time of $215 \mathrm{~ms}$. The predicted $\mathrm{m} / z$ value for the $[\mathrm{M}-\mathrm{H}]^{-}$ion of each analyte used for SIM are as follows: bactoprenyl phosphate (BP) 845.66, bactoprenyl phosphate-4-aminoarabinose (BPAra4N) 976.72, bactoprenyl phosphate-4-formamido-arabinose (BP-Ara4FN) 1004.71. For each analysis, 5-10 $\mu \mathrm{L}$ of total lipids were analyzed with a linear gradient starting with $15 \%$ solvent $\mathrm{C}$ and $85 \%$ solvent $\mathrm{D}$, raising to $75 \%$ solvent $C$ over $15 \mathrm{~min}$, then raising to $95 \%$ solvent $\mathrm{C}$ over $1 \mathrm{~min}$ and holding for $1 \mathrm{~min}$, and finally decreasing to $15 \%$ solvent $C$ over 3 min with a post run of $2 \mathrm{~min}$. Each analysis included a $3 \mathrm{~s}$ needle wash.

For the analysis of fluorescent $2 \mathrm{CN}-\mathrm{BP}$ and enzyme products with LC-MS, a TEE connector was used to split the solvent through both the MSD and FLD. Each of the four channels analyzed three SIM ions and one scan from 500-2000 m/z. MS parameters were the same as described above except the fragmentation voltage, which was set to $50 \mathrm{~V}$. The predicted $\mathrm{m} / \mathrm{z}$ value for the $[\mathrm{M}-\mathrm{H}]^{-}$ion of each analyte used for SIM are as follows: $2 \mathrm{CN}(6 Z) \mathrm{BP}$ 757.51, 2CN(6Z)BP-PentN 888.57, $2 \mathrm{CN}(6 Z) \mathrm{BP}-\mathrm{Hex}$ 919.56. For each analysis, 100-200 pmol of the starting material $(2 \mathrm{CN}(6 Z) \mathrm{BP})$ was analyzed with a linear gradient method starting with $25 \%$ solvent $C / 75 \%$ solvent $D$, raising to $65 \%$ solvent $\mathrm{C}$ over $10 \mathrm{~min}$ then decreasing back to $25 \%$ solvent $\mathrm{C}$ over 2 min with a 2 min post run.

ESI-MS-MS. To obtain the purified C41(DE3) membrane fraction product, a reaction containing $10 \mathrm{nmol} 2 \mathrm{CN}(6 Z) B P$ and $0.5 \mathrm{mg} / \mathrm{mL} \mathrm{C} 41(\mathrm{DE} 3)$ of the membrane fraction were incubated in buffered reaction conditions $(100 \mathrm{mM}$ Bicine $\mathrm{pH}$ 
8.0, $200 \mathrm{mM} \mathrm{KCl}, 15 \mathrm{mM}$ cholate, and $5 \mathrm{mM} \mathrm{MgCl}_{2}$ ) overnight at $37^{\circ} \mathrm{C}$. The unidentified product was then purified from the reaction mixture with RP-HPLC (condition A) using an Agilent Zorbax XBD-C18 column $(9.4 \mathrm{~mm} \times 250 \mathrm{~mm}, 5 \mu \mathrm{m}, 80 \AA$ ) , dried under vacuum, and resuspended in $n$-propanol and $25 \mathrm{mM}$ ammonium bicarbonate $(1: 1)$. The isolated product was then analyzed by MS using a VELOS Pro Dual-Pressure Linear Ion Trap with direct infusion $(100 \mu \mathrm{L} / \mathrm{min})$ in negative ion mode. MS was performed with a capillary voltage of $4 \mathrm{kV}$, capillary temperature of $200^{\circ} \mathrm{C}$, and in the range of $240-2000 \mathrm{~m} / z$. MS/ MS was performed by CID of the parent ion with an $m / z$ of 888.60

Cell Envelope Fraction Assays with 2CN-BP. To assess the transferase activity of E. coli C41(DE3) and MG1655 membrane fractions with $2 \mathrm{CN}(6 Z) \mathrm{BP}$, the membrane fractions $(0.5 \mathrm{mg} /$ $\mathrm{mL}$ total protein) were incubated with $2 \mathrm{CN}(6 \mathrm{Z}) \mathrm{BP}$ in reaction buffer at $37^{\circ} \mathrm{C}$ for $2 \mathrm{~h}$. Reactions contained $5 \mu \mathrm{M} 2 \mathrm{CN}(6 Z) \mathrm{BP}$ unless otherwise indicated. The turnover of $2 \mathrm{CN}-\mathrm{BP}$ was monitored by RP-HPLC and fluorescence detection. Inactivated wild-type C41(DE3) membrane fractions were prepared by heating wild-type membrane fractions to $95{ }^{\circ} \mathrm{C}$ for $20 \mathrm{~min}$. In experiments with inactivated membrane fractions, equivalent amounts $(0.5 \mathrm{mg} / \mathrm{mL}$ total protein $)$ of inactive and active membrane fractions were used.

Preparation of Total Lipids. To identify accumulated BP and BP-linked intermediates in wild-type and mutant E. coli MG1655 or C41(DE3), samples of total lipids were separated and analyzed by ESI-LC-MS. To prepare samples of total lipids, cultures consisting of $100 \mathrm{~mL}$ of Miller LB were prepared from a 1:1000 dilution of an overnight starter culture and grown to an $\mathrm{OD}_{595}$ of 1.0. In experiments with MG1655 and MG1655 $\Delta$ arnD, cells were cultured with or without $100 \mu \mathrm{M} \mathrm{FeSO}_{4}$. Cells were then pelleted at 15,000 RCF for $15 \mathrm{~min}$, resuspended in 1.6 $\mathrm{mL}$ of deionized water and transferred to glass centrifuge tubes. To aid in cell lysis and solubilization of prenyl and phospholipids, each cell suspension was mixed with $2 \mathrm{~mL}$ of chloroform and $4 \mathrm{~mL}$ of methanol to form a single-phase Bligh and Dyer solution (chloroform, methanol, water; 1:2:0.8 v/v). ${ }^{36}$ Cell suspensions were then vortexed and incubated at room temperature for $20 \mathrm{~min}$. Cell lysates were clarified of LPS and other contaminants by centrifugation at $2500 \times \mathrm{RCF}$ for $20 \mathrm{~min}$. The supernatant of each lysate was transferred to a glass culture tube and then dried under vacuum overnight. Dried samples were resuspended using $1 \mathrm{~mL}$ of BP uptake solution (hexanes, acetone, DMSO; 10:10:0.5) and vortexed. The soluble material was partitioned into a new glass culture tube and dried under vacuum. Dried samples were then resuspended in $200 \mu \mathrm{L}$ of a solution of $n$-propanol and $10 \mathrm{mM}$ ammonium hydroxide (1:1). Total lipids $(5-10 \mu \mathrm{L})$ were then analyzed by ESI-LC-MS in negative ion mode.

Preparation of Purified LPS from Wild-Type C41(DE3) Cells. Crude LPS from polymyxin -esistant E. coli C41(DE3) cells was obtained using a modified lipid A isolation procedure developed by Hankins et al. ${ }^{56}$ A $50 \mathrm{~mL}$ culture of C41(DE3) cells was grown in Miller LB broth at $37^{\circ} \mathrm{C}$ on a rotary shaker at $220 \mathrm{rpm}$ until reaching an $\mathrm{OD}_{595}$ of 1.0. Cells were pelleted for $15 \mathrm{~min}$ at $5000 \mathrm{RCF}$ and washed with $25 \mathrm{~mL}$ of $10 \mathrm{mM}$ phosphate buffered saline (PBS) $\mathrm{pH}$ 7.4. The cells were then resuspended in $3.2 \mathrm{~mL}$ PBS and divided equally between two $15 \mathrm{~mL}$ glass centrifuge tubes ( $1.6 \mathrm{~mL}$ of cell resuspension in each tube). To each glass centrifuge tube, $2 \mathrm{~mL}$ of chloroform and $4 \mathrm{~mL}$ of methanol was added to create a single-phase Bligh and Dyer solution. ${ }^{36}$ Tubes were vortexed and incubated for $20 \mathrm{~min}$ at room temperature. LPS along with insoluble proteins and nucleic acids were precipitated from the single-phase solution by centrifugation at $2000 \mathrm{RCF}$ for $20 \mathrm{~min}$. The supernatant was discarded, and the crude LPS pellet was washed with a second single-phase Bligh and Dyer solution (see above). The supernatant was discarded and the crude LPS pellet was dried under vacuum to remove any remaining solvent. The LPS pellet was then resuspended in $15 \mathrm{~mL}$ of $10 \mathrm{mM}$ Tris $-\mathrm{HCl} \mathrm{pH} 7.5$ and $15 \mathrm{mM} \mathrm{NaCl}$ with vigorous vortexing and sonication. The LPS pellet was then treated with $100 \mu \mathrm{g} / \mathrm{mL}$ of RNase A and incubated at $65^{\circ} \mathrm{C}$ for $30 \mathrm{~min}$. Once the solution cooled to room temperature, $1.5 \mathrm{mM} \mathrm{MgCl}_{2}, 0.5 \mathrm{mM} \mathrm{CaCl}_{2}$, and $50 \mathrm{U}$ of DNase I were added and the solution was incubated at $37^{\circ} \mathrm{C}$ for $30 \mathrm{~min}$. After $30 \mathrm{~min}, 100 \mu \mathrm{g} / \mathrm{mL}$ of proteinase $\mathrm{K}$ was added and the solution was incubated at $37{ }^{\circ} \mathrm{C}$ for $60 \mathrm{~min}$. Digested proteins and nucleic acids were removed from the LPS samples by converting the solution to a single-phase Bligh and Dyer solution and centrifugation at $5000 \mathrm{RCF}$ for $10 \mathrm{~min}$. The supernatant containing the digested proteins and nucleic acids was discarded, and the insoluble LPS precipitate was dried under vacuum. Finally, the dried LPS was resuspended in $1 \times$ PBS to a concentration of approximately $10 \mathrm{mg} / \mathrm{mL}$. Protein and nucleic acid contamination was evaluated by SDS-PAGE and staining with either Coomassie Blue, ethidium bromide, or silver stain. ${ }^{5}$

Testing Purified LPS as a Donor Substrate for ArnT. Reactions to test LPS as a Ara4N donor substrate contained 200 $\mathrm{mM}$ Bicine $\mathrm{pH}$ 8.0, $100 \mathrm{mM} \mathrm{KCl}, 5 \mathrm{mM} \mathrm{MgCl}, 15 \mathrm{mM}$ sodium cholate, $5.0 \mu \mathrm{M} 2 \mathrm{CN}(6 \mathrm{Z}) \mathrm{BP}, 0.5 \mathrm{mg} / \mathrm{mL}$ (total protein) of membrane fraction, and approximately $20 \mu \mathrm{g}$ of LPS unless otherwise specified. Reactions were incubated for $2 \mathrm{~h}$. at $37^{\circ} \mathrm{C}$ and monitored by fluorescence using RP-HPLC as previously described for the presence of $2 \mathrm{CN}(6 \mathrm{Z}) \mathrm{BP}-\mathrm{Ara} 4 \mathrm{~N}$. In a second experiment, incremental amounts of purified LPS $(20-80 \mu \mathrm{g})$ were added to reactions consisting of the same buffering conditions and incubated for $2 \mathrm{~h}$ prior to RP-HPLC analysis. To evaluate the activity of purified ArnT, $0.005 \mathrm{mg} / \mathrm{mL}$ of protein was incubated with $5 \mu \mathrm{M} 2 \mathrm{CN}(6 Z) B P$ in reaction buffer (described above) both with and without approximately $20 \mu \mathrm{g}$ of LPS. The reactions were monitored by fluorescence using RPHPLC (condition A) as previously described.

Transferase Assays with Native BP. To assess transferase activity of the $\Delta a r n C$ membrane fraction with native BP using wild-type LPS as a donor substrate, the $\triangle a r n C$ membrane fraction $(0.5 \mathrm{mg} / \mathrm{mL})$ was incubated in buffered reaction conditions (described above) with $500 \mu \mathrm{g}$ of LPS in a total volume of $500 \mu \mathrm{L}$. Reactions were then incubated for $2 \mathrm{~h}$ at 37 ${ }^{\circ} \mathrm{C}$ and extracted twice with $500 \mu \mathrm{L}$ of $n$-butanol. The upper phase was collected, dried under vacuum, and resuspended in 50 $\mu \mathrm{L}$ of $n$-propanol/10 $\mathrm{mM}$ ammonium hydroxide (1:1). The reactions were monitored for the formation of BP-Ara4N using ESI-LC-MS with SIM in negative ion mode.

Bacterial Strain Construction. Bacterial mutants (Table S1) were constructed by using the lambda red recombineering method of Datsenko and Wanner. ${ }^{58}$ In brief, parent strains MG1655 or C41 (DE3) were transformed with the plasmid $\mathrm{pKD} 46$. Transformants were grown to the log phase at $30^{\circ} \mathrm{C}$ in LB supplemented with $50 \mu \mathrm{g} / \mathrm{mL}$ carbenicillin and then induced by the addition of $100 \mathrm{mM}$ arabinose. After $1 \mathrm{~h}$ induction, bacteria were made electrocompetent by washing 3-6 times with ice-cold $0.3 \mathrm{M}$ sucrose and then resuspending in $0.3 \mathrm{M}$ sucrose at $\sim 1 / 50$ the original culture volume. This preparation was either transformed immediately or aliquoted and stored at $-80{ }^{\circ} \mathrm{C}$. To transform electrocompetent cells, $50 \mu \mathrm{L}$ cells were 
combined with purified PCR amplicon $(\sim 2 \mu \mathrm{g})$, generated as described below. This mixture was electroporated at $2500 \mathrm{~V}$ followed by the immediate addition of LB media. After overnight recovery at $30{ }^{\circ} \mathrm{C}$, cells were plated on $\mathrm{LB}$ agar with the appropriate selective media (chloramphenicol at $10-20 \mu \mathrm{g} / \mathrm{mL}$ for $\Delta a r n C:: c^{c a m}{ }^{R}$ and $\Delta a r n T:: \mathrm{cam}^{R}$; kanamycin at $50 \mu \mathrm{g} / \mathrm{mL}$ for $\left.\Delta a r n D:: k a n^{R}\right)$. Resistant colonies were evaluated by colony PCR to confirm the desired insertion. Primers for these reactions are listed in the Supporting Information (Table S2). To remove antibiotic resistance genes, strain CE356 or CE391 was transformed with pCP20, and streaked on LB agar with 50 $\mu \mathrm{g} / \mathrm{mL}$ carbenicillin for two successive single colony purifications, maintaining plates at $30{ }^{\circ} \mathrm{C}$. pCP20 was cured by restreaking each strain on plain $\mathrm{LB}$ agar and incubating plates at $37^{\circ} \mathrm{C}$ until sampled isolates exhibited sensitivity to carbenicillin and chloramphenicol/kanamycin (typically 3 days).

Molecular Cloning. Vector, restriction enzyme, and epitope tags used for each plasmid construct are listed in the Supporting Information (Table S3). Gene inserts were amplified from E. coli MG1655 using Phusion High-Fidelity DNA polymerase (ThermoFisher Scientific). Purified inserts and vector were ligated using T4 DNA ligase (Invitrogen) at room temperature for $30 \mathrm{~min}$. Cloning efficiency of arnT in $\mathrm{pET}-28 \mathrm{~b}$ was very poor and required incubation with T4 DNA ligase at $16^{\circ} \mathrm{C}$ for $16 \mathrm{~h}$. Ligation reactions were chemically transformed into $E$. coli DH5 $\alpha$ cells. Positive clones were confirmed with sequencing (Eurofins). For complementation assays, plasmids were transformed into chemically competent mutants. Cultures were supplemented with $0.1 \mathrm{mM}$ IPTG and $50 \mu \mathrm{g} / \mathrm{mL}$ of kanamycin from the time of inoculation.

Purification of ArnT. To solubilize the ArnT protein from the membrane fraction, we followed a previously reported procedure for the extraction of ArnT from Salmonella typhimurium expressed in E. coli. ${ }^{40}$ All steps of this protein purification occurred at $4{ }^{\circ} \mathrm{C}$ unless otherwise noted. A $5 \mathrm{~mL}$ culture of Miller LB broth supplemented with $50 \mu \mathrm{g} / \mathrm{mL}$ of kanamycin was inoculated from a single colony of C41(DE3) cells harboring the pArnT plasmid. Starter cultures were incubated overnight at $37^{\circ} \mathrm{C}$ with shaking at $220 \mathrm{rpm}$. Terrific broth (24 g yeast extract, $20 \mathrm{~g}$ tryptone, $0.4 \%$ glycerol, and 10 $\mathrm{mM}$ PBS in a total volume of $1 \mathrm{~L}$ ) containing $50 \mu \mathrm{g} / \mathrm{mL}$ of kanamycin were inoculated with a 1:1000 dilution of the starter culture and incubated at $37^{\circ} \mathrm{C}$ with shaking at $220 \mathrm{rpm}$. Protein expression was induced at an $\mathrm{OD}_{595}$ of 1.0 with $1 \mathrm{mM}$ IPTG. Cultures were then incubated overnight at $16^{\circ} \mathrm{C}$ with shaking at $220 \mathrm{rpm}$. Cells were pelleted at $5000 \mathrm{RCF}$ for $15 \mathrm{~min}$ and resuspended in buffer A containing $0.1 \% n$-dodecyl-maltoside (DDM). Resuspended cells were lysed with sonication (Fisher Sonic Dismembrator). Lysates were clarified with centrifugation at $5000 \mathrm{RCF}$ for $30 \mathrm{~min}$. The supernatant was then spun at $100,000 \mathrm{RCF}$ for $60 \mathrm{~min}$. Insoluble fractions were resuspended and homogenized in buffer A with 1.0\% DDM and placed on a spinner overnight at $4{ }^{\circ} \mathrm{C}$. Homogenate was clarified with ultracentrifugation at 100,000 RCF for $60 \mathrm{~min}$. The resulting supernatant was purified using $1 \mathrm{~mL}$ of Ni-NTA (Thermo Scientific). The fractions were then analyzed by SDS-PAGE and anti-His (GenScript) Western blotting.

Purification of ArnD. To overproduce and isolate ArnD, a 5 $\mathrm{mL}$ culture of Miller LB supplemented with $50 \mu \mathrm{g} / \mathrm{mL}$ of kanamycin was inoculated with a single colony of C41(DE3) cells harboring pArnD and grown overnight. Terrific broth (1 L) supplemented with $50 \mu \mathrm{g} / \mathrm{mL}$ of kanamycin was inoculated with a 1:1000 dilution of the overnight culture and incubated at $37^{\circ} \mathrm{C}$ with shaking at $220 \mathrm{rpm}$. Protein expression was induced with 1 mM IPTG at an $\mathrm{OD}_{595}$ of 0.6. Cells were then incubated at $30^{\circ} \mathrm{C}$ with shaking at $300 \mathrm{rpm}$ overnight. Cells were harvested at $15,000 \mathrm{RCF}$ for $15 \mathrm{~min}$ and resuspended in lysis buffer containing $1 \%$ Triton X-100. ${ }^{18}$ Resuspended cells were lysed by sonication (Fisher Sonic Dismembrator). Lysates were clarified with centrifugation at $5000 \mathrm{RCF}$ for $20 \mathrm{~min}$. The supernatant was then spun for $1 \mathrm{~h}$ at 150,000 RCF. ArnD was isolated from the supernatant with Ni-NTA affinity chromatography and assessed for protein content with SDS-PAGE and anti-His Western blotting. Fractions containing ArnD were dialyzed in buffer $\mathrm{B}$ and stored at $-80{ }^{\circ} \mathrm{C}$ until use.

ArnD Activity Analyses with Native BP-Ara4FN. To enable the characterization of $E$. coli $A r n D$, we used crude lipids prepared from MG1655 $\Delta a r n D$ cultured with $100 \mu \mathrm{M}$ FeSO4 as a source of native BP-Ara4FN substrate. To prepare lipids from MG1655 $\Delta a r n D$, single colonies cultured on LB/agar supplemented with $50 \mu \mathrm{g} / \mathrm{mL}$ of kanamycin were used to prepare $5 \mathrm{~mL}$ overnight cultures. Total lipids were prepared from $100 \mathrm{~mL}$ of cells at an $\mathrm{OD}_{595}$ of 1.0 as described above. To evaluate the activity of $\mathrm{ArnD}, 0.20 \mathrm{mg} / \mathrm{mL}$ of protein was added to reactions consisting of $50 \mathrm{mM}$ Hepes $\mathrm{pH} 7.0,100 \mathrm{mM} \mathrm{NaCl}$, $5 \mathrm{mM} \mathrm{MnCl}_{2}, 20 \mathrm{mM}$ DTT, and $2 \mu \mathrm{L}$ of MG1655 $\Delta$ arnD lipids in a total volume of $40 \mu \mathrm{L}$. Reactions were incubated at $30^{\circ} \mathrm{C}$ for $2 \mathrm{~h}$ and evaluated for the formation of BP-Ara4N using ESI-LCMS with $20 \mu \mathrm{L}$ injections as previously described.

\section{ASSOCIATED CONTENT}

\section{Supporting Information}

The Supporting Information is available free of charge at https://pubs.acs.org/doi/10.1021/acsomega.1c04036.

HPLC and ESI-LC-MS chromatograms, SDS-PAGE and Western blots of recombinant proteins, SDS-PAGE of LPS, strain list, primers used for mutagenesis, and primers and restriction sites used to prepare plasmid constructs (PDF)

\section{Accession Codes}

ArnC, P77757; ArnT, P76473; ArnD, P76472.

\section{AUTHOR INFORMATION}

\section{Corresponding Author}

Jerry M. Troutman - Department of Chemistry and Nanoscale Science Program, The University of North Carolina at Charlotte, Charlotte, North Carolina 28223-0001, United States; orcid.org/0000-0002-8340-462X; Phone: 704687-5180; Email: jtroutm3@uncc.edu

\section{Authors}

Beth A. Scarbrough - Nanoscale Science Program, The University of North Carolina at Charlotte, Charlotte, North Carolina 28223-0001, United States

Colleen R. Eade - Department of Chemistry, The University of North Carolina at Charlotte, Charlotte, North Carolina 28223-0001, United States

Amanda J. Reid - Nanoscale Science Program, The University of North Carolina at Charlotte, Charlotte, North Carolina 28223-0001, United States

Tiffany C. Williams - Department of Chemistry, The University of North Carolina at Charlotte, Charlotte, North Carolina 28223-0001, United States

Complete contact information is available at: https://pubs.acs.org/10.1021/acsomega.1c04036 


\section{Funding}

This work was supported by the National Institutes of Health R01GM123251 (JMT) and F31GM130065 (AJR).

\section{Notes}

The authors declare no competing financial interest.

\section{ACKNOWLEDGMENTS}

We thank Matthew Jorgenson (University of Arkansas for Medical Sciences) for providing E. coli MG1655 and for discussions about the project.

\section{ABBREVIATIONS}

$\mathrm{BP}$, bactoprenyl phosphate; CAMPs, cationic antimicrobial peptides; Ara4N, L-4-aminoarabinose; Ara4FN, L-4-formamido-arabinose; PGT, phospho-glycosyltransferase; 2CN-BP, 2nitrileanilinobactoprenyl phosphate; SIM, selected ion monitoring; LPS, lipopolysaccharide; DDM, $n$-dodecyl maltoside

\section{REFERENCES}

(1) Nummila, K.; Kilpeläinen, I.; Zahringer, U.; Vaara, M.; Helander, I. M. Lipopolysaccharides of polymyxin B-resistant mutants of Escherichia coli are extensively substituted by 2 -aminoethyl pyrophosphate and contain aminoarabinose in lipid A. Mol. Microbiol. 1995, 16, 271-278.

(2) Marr, N.; Tirsoaga, A.; Blanot, D.; Fernandez, R.; Caroff, M. Glucosamine found as a substituent of both phosphate groups in Bordetella lipid A backbones: role of a BvgAS-activated ArnT ortholog. J. Bacteriol. 2008, 190, 4281-4290.

(3) Zhou, Z.; Ribeiro, A. A.; Lin, S.; Cotter, R. J.; Miller, S. I.; Raetz, C. R. H. Lipid A modifications in polymyxin-resistant Salmonella typhimurium: PMRA-dependent 4-amino-4-deoxy-L-arabinose, and phosphoethanolamine incorporation. J. Biol. Chem. 2001, 276, 4311143121.

(4) Hamad, M. A.; Di Lorenzo, F.; Molinaro, A.; Valvano, M. A. Aminoarabinose is essential for lipopolysaccharide export and intrinsic antimicrobial peptide resistance in Burkholderia cenocepacia. Mol. Microbiol. 2012, 85, 962-974.

(5) Wang, X.; Ribeiro, A. A.; Guan, Z.; McGrath, S. C.; Cotter, R. J.; Raetz, C. R. H. Structure and biosynthesis of free lipid A molecules that replace lipopolysaccharide in Francisella tularensis subsp. novicida. Biochemistry 2006, 45, 14427-14440.

(6) Winfield, M. D.; Latifi, T.; Groisman, E. A. Transcriptional regulation of the 4-amino-4-deoxy-L-arabinose biosynthetic genes in Yersinia pestis. J Biol Chem 2005, 280, 14765-14772.

(7) Gunn, J. S.; Lim, K. B.; Krueger, J.; Kim, K.; Guo, L.; Hackett, M.; Miller, S. I. PmrA-PmrB-regulated genes necessary for 4-aminoarabinose lipid A modification and polymyxin resistance. Mol. Microbiol. 1998, 27, 1171-1182.

(8) Jayol, A.; Poirel, L.; Brink, A.; Villegas, M. V.; Yilmaz, M.; Nordmann, P. Resistance to colistin associated with a single amino acid change in protein PmrB among Klebsiella pneumoniae isolates of worldwide origin. Antimicrob. Agents Chemother. 2014, 58, 4762-4766.

(9) Nation, R. L.; Li, J.; Cars, O.; Couet, W.; Dudley, M. N.; Kaye, K. S.; Mouton, J. W.; Paterson, D. L.; Tam, V. H.; Theuretzbacher, U.; Tsuji, B. T.; Turnidge, J. D. Framework for optimisation of the clinical use of colistin and polymyxin B: the Prato polymyxin consensus. Lancet Infect. Dis. 2015, 15, 225-234.

(10) Harris, T. L.; Worthington, R. J.; Hittle, L. E.; Zurawski, D. V.; Ernst, R. K.; Melander, C. Small molecule downregulation of PmrAB reverses lipid A modification and breaks colistin resistance. ACS Chem. Biol. 2014, 9, 122-127.

(11) Kline, T.; Trent, M. S.; Stead, C. M.; Lee, M. S.; Sousa, M. C.; Felise, H. B.; Nguyen, H. V.; Miller, S. I. Synthesis of and evaluation of lipid A modification by 4-substituted 4-deoxy arabinose analogs as potential inhibitors of bacterial polymyxin resistance. Bioorg. Med. Chem. Lett. 2008, 18, 1507-1510.
(12) Raetz, C. R. H.; Reynolds, C. M.; Trent, M. S.; Bishop, R. E. Lipid A modification systems in gram-negative bacteria. Annu. Rev. Biochem. 2007, 76, 295-329.

(13) Breazeale, S. D.; Ribeiro, A. A.; Raetz, C. R. H. Origin of lipid A species modified with 4-amino-4-deoxy-L-arabinose in polymyxinresistant mutants of Escherichia coli: An aminotransferase (ArnB) that generates UDP-4-deoxyl-L-arabinose. J. Biol. Chem. 2003, 278, 2473124739.

(14) Breazeale, S. D.; Ribeiro, A. A.; McClerren, A. L.; Raetz, C. R. H. A formyltransferase required for polymyxin resistance in Escherichia coli and the modification of lipid A with 4-Amino-4-deoxy-L-arabinose. Identification and function oF UDP-4-deoxy-4-formamido-L-arabinose. J. Biol. Chem. 2005, 280, 14154-14167.

(15) Gatzeva-Topalova, P. Z.; May, A. P.; Sousa, M. C. Structure and mechanism of ArnA: conformational change implies ordered dehydrogenase mechanism in key enzyme for polymyxin resistance. Structure 2005, 13, 929-942.

(16) Lee, M.; Sousa, M. C. Structural basis for substrate specificity in ArnB. A key enzyme in the polymyxin resistance pathway of Gramnegative bacteria. Biochemistry 2014, 53, 796-805.

(17) Williams, G. J.; Breazeale, S. D.; Raetz, C. R. H.; Naismith, J. H. Structure and function of both domains of ArnA, a dual function decarboxylase and a formyltransferase, involved in 4-amino-4-deoxy-Larabinose biosynthesis. J. Biol. Chem. 2005, 280, 23000-23008.

(18) Adak, T.; Morales, D. L.; Cook, A. J.; Grigg, J. C.; Murphy, M. E. P.; Tanner, M. E. ArnD is a deformylase involved in polymyxin resistance. Chem. Commun. 2020, 56, 6830-6833.

(19) Yan, A.; Guan, Z.; Raetz, C. R. H. An undecaprenyl phosphateaminoarabinose flippase required for polymyxin resistance in Escherichia coli. J. Biol. Chem. 2007, 282, 36077-36089.

(20) Trent, M. S.; Ribeiro, A. A.; Lin, S.; Cotter, R. J.; Raetz, C. R. H. An inner membrane enzyme in Salmonella and Escherichia coli that transfers 4-amino-4-deoxy-L-arabinose to lipid A: induction on polymyxin-resistant mutants and role of a novel lipid-linked donor. $J$. Biol. Chem. 2001, 276, 43122-43131.

(21) Reid, A. J.; Scarbrough, B. A.; Williams, T. C.; Gates, C. E.; Eade, C. R.; Troutman, J. M. General Utilization of Fluorescent Polyisoprenoids with Sugar Selective Phosphoglycosyltransferases. Biochemistry 2020, 59, 615-626.

(22) Scott, P. M.; Erickson, K. M.; Troutman, J. M. Identification of the Functional Roles of Six Key Proteins in the Biosynthesis of Enterobacteriaceae Colanic Acid. Biochemistry 2019, 58, 1818-1830.

(23) Sharma, S.; Erickson, K. M.; Troutman, J. M. Complete Tetrasaccharide Repeat Unit Biosynthesis of the Immunomodulatory Bacteroides fragilis Capsular Polysaccharide A. ACS Chem. Biol. 2017, 12, 92-101.

(24) Trent, M. S.; Ribeiro, A. A.; Doerrler, W. T.; Lin, S.; Cotter, R. J.; Raetz, C. R. H. Accumulation of a polyisoprene-linked amino sugar in polymyxin-resistant Salmonella typhimurium and Escherichia coli: structural characterization and transfer to lipid A in the periplasm. $J$. Biol. Chem. 2001, 276, 43132-43144.

(25) Mann, E.; Whitfield, C. A widespread three-component mechanism for the periplasmic modification of bacterial glycoconjugates. Can. J. Chem. 2016, 94, 883-893.

(26) Rubin, E. J.; Herrera, C. M.; Crofts, A. A.; Trent, M. S. PmrD is required for modifications to escherichia coli endotoxin that promote antimicrobial resistance. Antimicrob. Agents Chemother. 2015, 59, 2051-2061.

(27) Froelich, J. M.; Tran, K.; Wall, D. A pmrA constitutive mutant sensitizes Escherichia coli to deoxycholic acid. J. Bacteriol. 2006, 188, $1180-1183$.

(28) Groisman, E. A. The pleiotropic two-component regulatory system PhoP-PhoQ. J. Bacteriol. 2001, 183, 1835-1842.

(29) Cannatelli, A.; Giani, T.; Aiezza, N.; Di Pilato, V.; Principe, L.; Luzzaro, F.; Galeotti, C. L.; Rossolini, G. M. An allelic variant of the $\mathrm{PmrB}$ sensor kinase responsible for colistin resistance in an Escherichia coli strain of clinical origin. Sci. Rep. 2017, 7, 5071. 
(30) Wosten, M. M.; Kox, L. F.; Chamnongpol, S.; Soncini, F. C.; Groisman, E. A. A signal transduction system that responds to extracellular iron. Cell 2000, 103, 113-125.

(31) Zhou, Z.; Lin, S.; Cotter, R. J.; Raetz, C. R. H. Lipid A modifications characteristic of Salmonella typhimurium are induced by $\mathrm{NH}_{4} \mathrm{VO}_{3}$ in Escherichia coli K12. Detection of 4-amino-4-deoxy-Larabinose, phosphoethanolamine and palmitate. J. Biol. Chem. 1999, 274, 18503-18514.

(32) Hagiwara, D.; Yamashino, T.; Mizuno, T. A Genome-wide view of the Escherichia coli BasS-BasR two-component system implicated in iron-responses. Biosci., Biotechnol., Biochem. 2004, 68, 1758-1767.

(33) Gibbons, H. S.; Kalb, S. R.; Cotter, R. J.; Raetz, C. R. H. Role of $\mathrm{Mg} 2+$ and $\mathrm{pH}$ in the modification of Salmonella lipid A after endocytosis by macrophage tumour cells. Mol. Microbiol. 2005, 55, $425-440$.

(34) Song, F.; Guan, Z.; Raetz, C. R. H. Biosynthesis of undecaprenyl phosphate-galactosamine and undecaprenyl phosphate-glucose in Francisella novicida. Biochemistry 2009, 48, 1173-1182.

(35) Guan, S.; Bastin, D. A.; Verma, N. K. Functional analysis of the O antigen glucosylation gene cluster of Shigella flexneri bacteriophage SfX. Microbiology 1999, 1263.

(36) Bligh, E. G.; Dyer, W. J. A rapid method of total lipid extraction and purification. Can. J. Biochem. Physiol. 1959, 37, 911-917.

(37) Henderson, J. C.; O’Brien, J. P.; Brodbelt, J. S.; Trent, M. S. Isolation and chemical characterization of lipid A from gram-negative bacteria. J. Visualized Exp. 2013, 79, No. e50623.

(38) Jeong, H.; Barbe, V.; Lee, C. H.; Vallenet, D.; Yu, D. S.; Choi, S.H.; Couloux, A.; Lee, S. W.; Yoon, S. H.; Cattolico, L.; Hur, C. G.; Park, H. S.; Ségurens, B.; Kim, S. C.; Oh, T. K.; Lenski, R. E.; Studier, F. W.; Daegelen, P.; Kim, J. F. Genome sequences of Escherichia coli B strains REL606 and BL21(DE3). J. Mol. Biol. 2009, 394, 644-652.

(39) Jansson, P. E.; Lindberg, A. A.; Lindberg, B.; Wollin, R. Structural studies on the hexose region of the core in lipopolysaccharides from Enterobacteriaceae. Eur. J. Biochem. 1981, 115, 571-577.

(40) Bretscher, L. E.; Morrell, M. T.; Funk, A. L.; Klug, C. S. Purification and characterization of the L-Ara4N transferase protein ArnT from Salmonella typhimurium. Protein Expression Purif. 2006, 46, 33-39.

(41) Petsch, D.; Anspach, F. B. Endotoxin removal from protein solutions. J. Biotechnol. 2000, 76, 97-119.

(42) Olagnon, C.; Monjaras Feria, J.; Grunwald-Gruber, C.; Blaukopf, M.; Valvano, M. A.; Kosma, P. Synthetic Phosphodiester-Linked 4Amino-4-deoxy-l-arabinose Derivatives Demonstrate that ArnT is an Inverting Aminoarabinosyl Transferase. ChemBioChem 2019, 20, 2936-2948.

(43) Barr, K.; Rick, P. D. Biosynthesis of enterobacterial common antigen in Escherichia coli. In vitro synthesis of lipid-linked intermediates. J. Biol. Chem. 1987, 262, 7142-7150.

(44) Cartee, R. T.; Forsee, W. T.; Bender, M. H.; Ambrose, K. D.; Yother, J. CpsE from type 2 Streptococcus pneumoniae catalyzes the reversible addition of glucose-1-phosphate to a polyprenyl phosphate acceptor, initiating type 2 capsule repeat unit formation. J. Bacteriol. 2005, 187, 7425-7433.

(45) Osborn, M. J.; Tze-Yuen, R. Y. Biosynthesis of bacterial lipopolysaccharide. VII. Enzymatic formation of the first intermediate in biosynthesis of the O-antigen of Salmonella typhimurium. J. Biol. Chem. 1968, 243, 5145-5152.

(46) Gantt, R. W.; Peltier-Pain, P.; Singh, S.; Zhou, M.; Thorson, J. S. Broadening the scope of glycosyltransferase-catalyzed sugar nucleotide synthesis. Proc. Natl. Acad. Sci. U. S. A. 2013, 110, 7648-7653.

(47) Chng, S. S.; Gronenberg, L. S.; Kahne, D. Proteins required for lipopolysaccharide assembly in Escherichia coli form a transenvelope complex. Biochemistry 2010, 49, 4565-4567.

(48) Sherman, D. J.; Xie, R.; Taylor, R. J.; George, A. H.; Okuda, S.; Foster, P. J.; Needleman, D. J.; Kahne, D. Lipopolysaccharide is transported to the cell surface by a membrane-to-membrane protein bridge. Science 2018, 359, 798-801.

(49) Whitfield, C.; Trent, M. S. Biosynthesis and export of bacterial lipopolysaccharides. Annu. Rev. Biochem. 2014, 83, 99-128.
(50) Owens, T. W.; Taylor, R. J.; Pahil, K. S.; Bertani, B. R.; Ruiz, N.; Kruse, A. C.; Kahne, D. Structural basis of unidirectional export of lipopolysaccharide to the cell surface. Nature 2019, 567, 550-553.

(51) Paradis-Bleau, C.; Kritikos, G.; Orlova, K.; Typas, A.; Bernhardt, T. G. A genome-wide screen for bacterial envelope biogenesis mutants identifies a novel factor involved in cell wall precursor metabolism. PLoS Genet. 2014, 10, No. e1004056.

(52) Jorgenson, M. A.; Kannan, S.; Laubacher, M. E.; Young, K. D. Dead-end intermediates in the enterobacterial common antigen pathway induce morphological defects in Escherichia coli by competing for undecaprenyl phosphate. Mol. Microbiol. 2016, 100, 1-14.

(53) Jorgenson, M. A.; Young, K. D. Interrupting Biosynthesis of O Antigen or the Lipopolysaccharide Core Produces Morphological Defects in Escherichia coli by Sequestering Undecaprenyl Phosphate. J. Bacteriol. 2016, 198, 3070-3079.

(54) Kahler, C. M.; Sarkar-Tyson, M.; Kibble, E. A.; Stubbs, K. A.; Vrielink, A. Enzyme targets for drug design of new anti-virulence therapeutics. Curr. Opin. Struct. Biol. 2018, 53, 140-150.

(55) Troutman, J. M.; Erickson, K. M.; Scott, P. M.; Hazel, J. M.; Martinez, C. D.; Dodbele, S. Tuning the production of variable length, fluorescent polyisoprenoids using surfactant-controlled enzymatic synthesis. Biochemistry 2015, 54, 2817-2827.

(56) Hankins, J. V.; Madsen, J. A.; Needham, B. D.; Brodbelt, J. S.; Trent, M. S. The outer membrane of Gram-negative bacteria: lipid A isolation and characterization. Methods Mol. Biol. 2013, 966, 239-258.

(57) Fomsgaard, A.; Freudenberg, M. A.; Galanos, C. Modification of the silver staining technique to detect lipopolysaccharide in polyacrylamide gels. J. Clin. Microbiol. 1990, 28, 2627-2631.

(58) Datsenko, K. A.; Wanner, B. L. One-step inactivation of chromosomal genes in Escherichia coli K-12 using PCR products. Proc. Natl. Acad. Sci. U. S. A. 2000, 97, 6640-6645. 